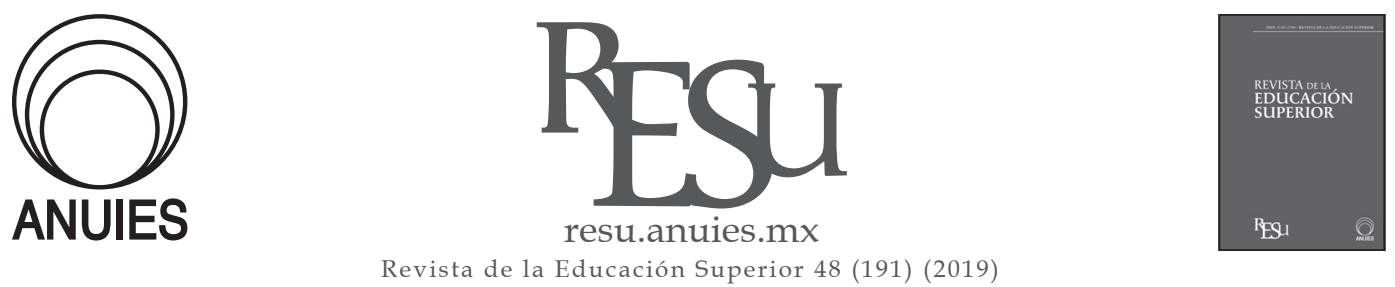

ARTí́CULO

\title{
Caracterización del desempeño laboral de los egresados y la segmentación de cuatro mercados en Ciudad Juárez
}

\section{Graduates Characterization Work performance and four markets segmentation in Ciudad Juárez}

\author{
Ramsés Jiménez Castañeda* \\ * Universidad Autónoma de Ciudad Juárez, Ciudad Juárez, Chihuahua, México. \\ Correo electrónico: rjimenez@uacj.mx
}

Recibido el 03 de septiembre del 2018; aceptado el 31 de julio del 2019

\begin{abstract}
Resumen
Este trabajo muestra el desempeño de profesionistas en 4 mercados laborales de Ciudad Juárez. Se retoma la Teoría de Segmentación de Mercado de Trabajo complementada a través un índice de desempeño laboral. Se estudia a los egresados que cuentan con trabajo de una universidad pública del norte de México. Se verifica, a través de una modelación econométrica, evidencia sobre la diferencia del desempeño y su significancia para la segmentación. Los resultados arrojados sugieren efectos contrastantes en algunos de los programas educativos (egresados) respecto a los 4 mercados estudiados.
\end{abstract}

Palabras clave: Mercado laboral segmentado; Desempeño; Condición laboral; Trayectorias de egresados 


\begin{abstract}
This work shows the professionals performance in 4 labor markets of Ciudad Juárez. The Labor Market Segmentation Theory is complemented by an index of labor performance. Graduates from a public university in northern Mexico who have a job are studied. Evidence on the difference of performance and its significance for segmentation is verified through econometric modeling. The results show contrasting effects in some of the educational programs (graduates) related to the 4 markets studied.
\end{abstract}

Keywords: Segmented labor market; Performance; Work condition; Graduates trajectories

\title{
Introducción
}

$\mathrm{E}$

n México difícilmente se encuentran mercados laborales homogéneos, ya que hay regiones en donde el mercado tiene mayor capacidad de absorción para las personas que intentan colocarse en él; hay otras regiones donde resulta más difícil por la falta de empresas o mercado. Aquellas personas que viven en regiones donde puedan emplearse con mayor facilidad, por lo regular lo hacen bajo condiciones laborales inadecuadas.

En este sentido, Maza Díaz (2013) define el mercado laboral como el espacio donde existen fuerzas o condiciones de oferta y demanda, pero no sólo se limita a esto. Para Camberos y Yáñez (2003) el desequilibrio del mercado laboral generaría desempleo (voluntario o involuntario). Sus características revelarían el funcionamiento de la economía de manera agregada( Maza Díaz, 2013); . Existen diferentes enfoques para analizar el mercado laboral y cada uno enfatiza diferentes elementos, algunos de ellos son: el modelo neoclásico, el modelo clásico, el nuevo modelo clásico, el Keynesiano, el Marxista y el de mercados segmentados, entre otros . El mercado de trabajo segmentado es la perspectiva teórica utilizada en este trabajo.

Una de los primeros trabajos de este enfoque fue el que refirió Piore (1969) citado por , quien caracterizaba el mercado de trabajo de manera dual. Reconocía la existencia de un mercado primario que ofrece salarios relativamente altos, trabajo estable con buenas condiciones y oportunidades de ser promovido. A su vez también reconocía el mercado secundario que era definido como puestos de trabajo menos atractivos en todos los aspectos. Posterior- 
mente Piore (1975) expande su visión del mercado de trabajo, dividiendo el sector primario en un segmento superior y otro inferior: el primero contiene los puestos de trabajo asociados a profesionales y cargos directivos (trabajadores de cuello blanco), mientras que el segmento inferior incluye aquéllos con características manuales (trabajadores de cuello azul) ; .

Así, Fernández (2010), citando a Piore (1975), utiliza este enfoque y lo explica de la siguiente manera:

El mercado segmentado se divide en dos sectores, el mercado primario (formal) y el secundario (informal). El primero asume los puestos que tienen salarios elevados, y se divide en dos subsectores, el superior y el inferior. El superior comprende puestos profesionales, que además de tener salarios altos, también tiene mayores posibilidades de ser promovido. El inferior se caracteriza por tener empleados con puestos con características manuales. El mercado secundario es el que incluye puestos donde los salarios son bajos y existen pocas probabilidades de ser promovido. (Fernández, 2010: 120)

La manera de ver la participación laboral en un mercado (o varios) dependerá de las personas. Existen diferentes niveles de inversión en capital humano: aquellos que han invertido en formar su capacidad productiva obtendrán recompensas laborales más elevadas y sus ingresos crecen más, en comparación con los que han invertido menos en su formación. Sin embargo, la afirmación anterior podría no ser del todo válida. La tsm sostiene que el mercado de trabajo no es un solo mercado competitivo, sino que está compuesto por una variedad de segmentos no competitivos entre los cuales las remuneraciones al capital humano difieren. Existen barreras institucionales que limitan a la población de beneficiarse equitativamente de la educación y capacitación .

Así mismo, Lehmann y Pignatti (2007) encuentran que mientras los trabajadores intentan ingresar al empleo formal, algunos se ven obligados a aceptar empleos informales de manera involuntaria aun cuando tienen la misma inversión en capital humano respecto a los que sí están colocados en un empleo formal . Otra manera de interpretar la segmentación del mercado es realizar una distinción entre los empleos como posiciones en el mercado de trabajo, de las recompensas y de las características que los distinguen entre sí. El primer aspecto tiene que ver con el reconocimiento a partir de conjuntos de puestos, o segmentos que comparten características altamente similares entre sí. El segundo aspecto tiene que ver con la presencia de secuencias típicas o trayectorias de movilidad . 
Para visualizar de manera gráfica cómo se compone el enfoque de la segmentación de mercado que se utilizara en este trabajo, se muestra la figura 1:

Figura 1. Mercado laboral segmentado.

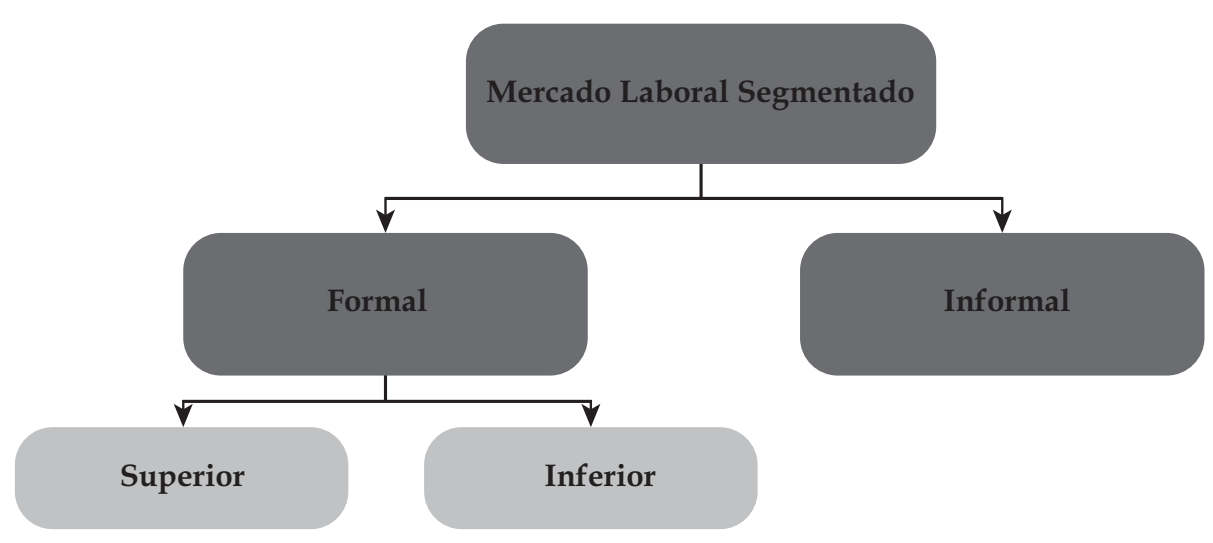

Fuente: Elaboración propia con información de Piore, 1972 y Fernández \& Agüera, 2012

Las razones por las que un mercado de trabajo se segmenta, en lugar de existir un sólo mercado competitivo, es asumir que los salarios en algunas empresas son mayores que el nivel de equilibrio. Una de las razones asume que las empresas no se rigen exclusivamente por la maximización de beneficios, más bien por reglas institucionales y por otras necesidades. Las empresas no necesariamente fijan sus salarios en función a la productividad marginal, ya que requiere hacer inversiones de capital humano en sus trabajadores. De lo anterior, sería inútil dicha inversión si el trabajador rotara. La forma en que las empresas lo hacen, es fijando los salarios por encima del nivel de equilibrio aumentando el costo de oportunidad de sus empleados .

Un efecto complementario en la segmentación se origina a partir de dos eventos: primero, la fuerza laboral urbana aumenta a partir de procesos migratorios hacia las ciudades; segundo, un sector moderno (industrial) crece a menor ritmo que la misma fuerza de trabajo, lo que implica crear menos puestos de los requeridos y que complete una absorción de mano de obra. El resultado es un "excedente de fuerza de trabajo" que mantiene desempleo, el cual debe de autogenerar su empleo o emplearse en empresas con características contrarias al sector industrial .

La situación del trabajo en la frontera norte de México mostró que el 75.2\% de los trabajadores eran empleados y obreros. Este aspecto implica que sí se genera trabajo, pero se hace más para trabajadores del subsector secundario .

No cabe duda de que el empleo en México ha aumentado, pero entre finales de la década de los 90 y principios de la presente también lo ha hecho 
la cantidad de egresados de educación superior. Desafortunadamente la economía no ha crecido proporcionalmente; no se han producido los empleos requeridos en los mercados de trabajo para poder colocar a los profesionistas que cada año egresan . Para el caso de Ciudad Juárez, ésta ha tenido modificaciones importantes en crecimiento y desarrollo. Estudios sobre la estructura económica local identificaron requerimientos de capital humano desarrollando entre dos patrones, por un lado, la industria maquiladora caracterizando una economía especializada, pero también una economía local mucho más diversificada y orientada hacia el sector de comercio y servicios. La principal característica del mercado laboral del municipio de Juárez es la concentración de una gran cantidad de trabajadores y su disponibilidad en el mercado laboral .

De esta manera, creemos que es importante analizar la trayectoria que tienen los egresados que están colocados en el mercado laboral y conocer si existe un cambio en la segmentación desde el punto de vista del programa educativo al que egresan.

La trayectoria del individuo se refiere a las diferentes etapas que experimenta una vez finalizada su formación, atendiendo a una profesión específica en relación a la inserción laboral. Un gran número de instituciones de educación superior no cuentan con programas de seguimiento de egresados; de esta forma no pueden verificar la pertinencia de la formación de sus graduados y su relación con el campo profesional. Evaluar resulta relevante en la toma de decisiones en futuros egresados, ya que los programas educativos y graduados universitarios se enfrentan constantemente a diversos obstáculos para lograr ingresar al mercado laboral y permanecer sostenidamente .

De esta manera, las trayectorias laborales de los egresados permiten saber la mejor opción de las actividades específicas que éstos realizan, cómo pueden tener una mejor ocupación y una relación con las instituciones, sus redes y sus características de empleo, para así aumentar y conservar el capital social y cultural proporcionando apoyo al proceso de ingreso del mercado laboral.

\section{El desempeño de los egresados en los mercados estudiados: una aportación metodológica del desempeño.}

Los estudios de egresados contribuyen a la sistemática y continua evaluación de las instituciones de educación superior. Estos proyectos producen prácticamente procesos de innovación, novedosos métodos de enseñanza- 
aprendizaje y la eficiencia de recursos; permiten sustraer información y características del desempeño profesional a través de opiniones y sugerencias sobre la calidad de la educación adquirida y de las nuevas demandas del mercado laboral .

Recientemente ha mencionado Durán (2017) que lamentablemente en México no se brinda información de manera homogénea y sistemática de los egresados universitarios; algunas instituciones educativas elaboran estudios de seguimiento con esfuerzos aislados. No existe un sistema nacional (o por lo menos regional) que intente evaluar, analizar y comprender los resultados de formación profesional a cerca de los individuos que intentan colocarse en el mercado laboral durante o concluida su educación superior .

En Cd. Juárez, a pesar de que existe información acerca de las condiciones laborales de los egresados, no hay suficiente investigación que muestre el grado de inserción de los programas educativos de instituciones públicas o privadas. Este trabajo intenta precisamente reducir este déficit, y para ello se retoman las ideas de Burgos y López $(2010,2012)$ y de Burgos (2008), para construir un Índice de Desempeño Laboral (IDL) donde se rescatan los resultados de la encuesta de Padrón de Egreso (PE) y Seguimiento de Egresados (PS) de una universidad pública para los años 2006 al 2014.

Para crear el IDL se toman en cuentan 5 variables como las que proponen Burgos y López (2010), con la diferencia --ellos la denominan índice de pertinencia laboral-- de la estructura de la información y la diferencia significativa en los programas educativos. Tales variables caracterizan el mercado de trabajo de los profesionistas y tipifican los diversos programas educativos en función de la adecuada integración de sus egresados al mercado de trabajo.

La primera variable es construida a partir de los salarios mínimos (SM) que representa el ingreso mensual neto declarado por los egresados; se divide en rangos de dos categorías: entre 1 y 6 SM, y de 7 o más SM. Se indica la segmentación de los egresados por programa educativo a través de los rangos del ingreso. Se divide en un rango de 1 a 6 SM para la encuesta de Padrón de Egreso. Los recién egresados por lo general no esperan tener un salario muy elevado ni estar colocados en el sector formal superior. Para el caso de la encuesta de Seguimiento a Egresados (dos años de haber egresado), ahora se toman en cuenta aquellos que reportan tener 7 o más SM, ya que ese nivel salarial representa una mayor posibilidad de estar colocado en el sector formal superior asumiendo la segmentación del programa educativo a través de sus graduados. La proporción de los rangos salariales de 1 a 6 y 7 o más son $60 \%$ y $40 \%$, respectivamente. Así, esta variable ayuda a captar el cambio de un sector formal inferior al formal superior desde la perspectiva de SMT. 
Las siguientes variables revelan la condición de estar colocado en el sector superior, dado las condiciones con las que se construyen.

La segunda variable es el tipo de puesto ocupado que consideras los diferentes puestos de los egresados en dos categorías. La primera corresponde al tipo de puesto que tienen "presumiblemente requerimientos de educación profesional", como director general, dueño de empresa/despacho, educación, empleado profesional, funcionario/administrador, gerente/director de área, jefe de oficina/sección/área, profesional independiente y subgerente/ subdirector de área. La segunda categoría agrupa puestos que "no requieren presumiblemente educación profesional", como análisis técnico, artes, deportes, artesanos y trabajadores fabriles, asistente/ayudante/auxiliar, comerciante o empleado de comercio, empleado doméstico, empleado no profesional, jornalero agrícola, mando medio administrativo, operadores de maquinaria, por cuenta propia no profesional, servicios domésticos, servicios profesionales (estilistas, etc.), técnico especializado, trabajador de protección y vigilancia, trabajar manual no calificado y vendedor. Se toman en cuenta la cantidad de egresados que están en la primera categoría, lo cual refleja que están colocados en el sector formal superior.

La tercera variable identifica a los egresados universitarios que ocupan puestos que no requieren educación profesional. Se elabora a partir de la variable "vinculación con el mercado". El instrumento viene predeterminado del 0 al 10 (tipo Likert), donde 0 corresponde que el egresado no está nada vinculado a su trabajo, hasta 10 que tiene que ver con que está excelentemente vinculado. Para asemejar esta variable a la teoría relevante (tener educación profesional, la cual no fue un requisito para obtener su trabajo actual), se establecen 5 grupos. "Excelente" conforma la cantidad de egresados con una vinculación al mercado total. "Adecuada" refiere los egresados con una vinculación a su mercado de 7,8 y 9. "Regular", egresados que dijeron tener una vinculación al mercado de 4, 5 y 6. "Insuficiente", los egresados con una vinculación de mercado en 1, 2 y 3. Por último, "Nada" es la cantidad de egresados que reportan tener una vinculación de mercado de 0 . Cuando tener educación profesional no fue un requisito, se considera al profesionista como sobre educado. Se toman en cuenta la cantidad de egresados que tienen una vinculación de excelente y adecuada, lo cual refleja que están colocados en el sector formal superior.

La cuarta variable es el grado de coincidencia del programa educativo con el puesto desempeñado. Se compone con la respuesta a la pregunta ¿En qué medida coincide su trabajo actual con sus estudios? El instrumento contiene respuestas predeterminadas de "total, mucho, mediana, parcial, baja y 
nada". Se considera la cantidad de egresados que reportan una coincidencia de mediana, parcial, mucho o total, lo cual refleja que están colocados en el sector formal superior.

La quinta variable complementa la anterior en el sentido de que refleja el "desfase de conocimientos". Es calculada a partir del promedio de las respuestas a las preguntas ¿qué tan buena fue la formación teórica, metodológica y practica? obtenida en la UACJ. Las tres formaciones tienen un rango de respuesta de 1 a 10, siendo 1 mala y 10 excelente. Una vez calculado el promedio, para adecuarse a la teoría SMT, se toman en cuenta la cantidad de egresados que obtienen un promedio de 7 a 10, lo cual refleja que utilizan de excelente a regular sus conocimientos adquiridos, colocándolos en el sector formal superior. Los egresados que utilizan poco o nada de lo aprendido en la UACJ estarían en situación de desfase de conocimientos.

Dicho IDL se construye a partir de calcular la proporción de egresados que se encuentran en una situación definida como adecuada en cada una de las cinco variables. Es normalizado por la cantidad de egresados que trabajan en cada sector para cada programa educativo. Representa un indicador que toma valores del 0 al 100, siendo 100 el desempeño ideal. En la ecuación (1) se muestra la composición del IDL:

Ecuación 1. Índice de Desempeño Laboral.

\section{Donde:}

$I D L j=$ Índice de desempeño laboral.

$j=$ Programa educativo.

$n=$ Número de variables consideradas (5).

$0 j=$ Cantidad de egresados que trabajan.

$W j=$ Cantidad de egresados que trabajan con ingresos de 1 a 6 SM (egreso) y 7 SM o más (seguimiento).

$P j=$ Cantidad de egresados que trabajan en puestos que presumiblemente requieren de educación profesional.

$R j=$ Cantidad de egresados que trabajan para los que tener una carrera universitaria fue un requisito en su empleo.

$C j=$ Cantidad de egresados que trabajan que su actividad laboral tiene de mediana a total coincidencia con sus estudios.

$M j=$ Cantidad de egresados ocupados que utilizan mucho y regular los conocimientos y habilidades adquiridos.

Se calcula el IDL para cada programa educativo a partir de (1). Utilizamos los datos de la encuesta de Padrón de Egreso (2006 al 2014) para los mercados de industrial, servicios y comercio, educación y salud. El mercado "industrial" integra las ramas laborales industria de la construcción, industria manufacturera 
nacional e industria maquiladora. El de "servicios y comercio" las ramas, comercio, comercios y restaurantes, comunicaciones, transportes y almacenes, servicio de alquiler de bienes, servicio de esparcimiento recreativo y deportivo, servicio de infraestructura (agua, gas y electricidad), servicio de reparación y otros servicios personales, servicio financiero, servicios, servicios profesionales y servicios turísticos y almacenes. La "educación" se compone de educación y servicio educativo. Finalmente, el mercado de "salud" constituye las ramas del sector público y privado, servicios médicos.

Estos 4 mercados representan el 86\% del mercado en donde se colocan los egresados de la UACJ. El 14\% restante refiere ramas laborales como agrícola, ganadero (en el cual solamente se coloca aproximadamente el $0.6 \%$ de los egresados), sector público, sector privado sin información específica, por lo cual no se pueden categorizar en ninguno de los mercados estudiados.

Cada sector está conformado por distintos programas educativos (divididos por área de conocimiento, ciencias sociales y administración, ingenierías y ciencias biomédicas). Una condición que se tomó para efectos de robustez, es que el programa educativo sea considerado en cada mercado sobre su IDL mayor a 0 en por lo menos 6 años. A continuación se muestran los resultados obtenidos por programa educativo para cada mercado. La tabla 1. enseña la información del IDL para los programas educativos dentro del mercado industrial (24 programas), así como la desagregación de las variables que lo conforman.

Tabla 1. Índice de Desempeño Laboral para el mercado industrial.

\begin{tabular}{|c|c|c|c|c|c|c|c|}
\hline $\begin{array}{l}\text { Programa } \\
\text { Educativo }\end{array}$ & $\begin{array}{c}\text { Tipo de } \\
\text { Encuesta }\end{array}$ & $\begin{array}{c}\text { Nivel } \\
\text { Salarial }\end{array}$ & $\begin{array}{l}\text { Tipo de } \\
\text { Puesto }\end{array}$ & Vinculación & $\begin{array}{c}\text { Coincidencia } \\
\text { Programa - } \\
\text { Empleo }\end{array}$ & $\begin{array}{l}\text { Coincidencia } \\
\text { Conocimiento } \\
\text { - Empleo }\end{array}$ & IDL \\
\hline \multirow{2}{*}{$\begin{array}{l}\text { Médico } \\
\text { Cirujano }\end{array}$} & Egreso & $63.2 \%$ & $60.5 \%$ & $47.4 \%$ & $42.1 \%$ & $94.7 \%$ & $61.6 \%$ \\
\hline & Seguimiento & $100 \%$ & $100 \%$ & $83.3 \%$ & $100 \%$ & $100 \%$ & $96.7 \%$ \\
\hline \multirow{2}{*}{ Enfermería } & Egreso & $53.8 \%$ & $51.3 \%$ & $43.6 \%$ & $48.7 \%$ & $87.2 \%$ & $56.9 \%$ \\
\hline & Seguimiento & $76.7 \%$ & $66.7 \%$ & $76.7 \%$ & $90.0 \%$ & $100 \%$ & $82.0 \%$ \\
\hline \multirow{2}{*}{$\begin{array}{l}\text { Ingeniería en } \\
\text { Mecatrónica }\end{array}$} & Egreso & $49.4 \%$ & $82.8 \%$ & $45.4 \%$ & $66.7 \%$ & $79.3 \%$ & $64.7 \%$ \\
\hline & Seguimiento & $66.3 \%$ & $88.4 \%$ & $77.9 \%$ & $87.2 \%$ & $96.5 \%$ & $83.3 \%$ \\
\hline \multirow{2}{*}{$\begin{array}{l}\text { Diseño } \\
\text { Industrial }\end{array}$} & Egreso & $47.4 \%$ & $71.9 \%$ & $50.9 \%$ & $73.7 \%$ & $86.0 \%$ & $66.0 \%$ \\
\hline & Seguimiento & $72.2 \%$ & $83.3 \%$ & $83.3 \%$ & $81.5 \%$ & $98.1 \%$ & $83.7 \%$ \\
\hline \multirow{2}{*}{$\begin{array}{l}\text { Ingeniería } \\
\text { Industrial y de } \\
\text { Sistemas }\end{array}$} & Egreso & $45.9 \%$ & $78.8 \%$ & $65.3 \%$ & $86.1 \%$ & $79.9 \%$ & $71.2 \%$ \\
\hline & Seguimiento & $66.4 \%$ & $84.3 \%$ & $91.8 \%$ & $95.9 \%$ & $98.5 \%$ & $87.4 \%$ \\
\hline
\end{tabular}




\begin{tabular}{|c|c|c|c|c|c|c|c|}
\hline $\begin{array}{l}\text { Programa } \\
\text { Educativo }\end{array}$ & $\begin{array}{l}\text { Tipo de } \\
\text { Encuesta }\end{array}$ & $\begin{array}{c}\text { Nivel } \\
\text { Salarial }\end{array}$ & $\begin{array}{l}\text { Tipo de } \\
\text { Puesto }\end{array}$ & Vinculación & $\begin{array}{c}\text { Coincidencia } \\
\text { Programa - } \\
\text { Empleo }\end{array}$ & $\begin{array}{l}\text { Coincidencia } \\
\text { Conocimiento } \\
\text { - Empleo }\end{array}$ & IDL \\
\hline \multirow{2}{*}{ Química } & Egreso & $44.4 \%$ & $77.8 \%$ & $50.0 \%$ & $83.3 \%$ & $88.9 \%$ & $68.9 \%$ \\
\hline & Seguimiento & $70.6 \%$ & $70.6 \%$ & $88.2 \%$ & $100 \%$ & $94.1 \%$ & $84.7 \%$ \\
\hline \multirow{2}{*}{$\begin{array}{l}\text { Ingeniería en } \\
\text { Sistemas Com- } \\
\text { putacionales }\end{array}$} & Egreso & $50.5 \%$ & $60.7 \%$ & $67.3 \%$ & $73.8 \%$ & $79.4 \%$ & $66.4 \%$ \\
\hline & Seguimiento & $64.0 \%$ & $67.5 \%$ & $86.8 \%$ & $86.8 \%$ & $98.2 \%$ & $80.7 \%$ \\
\hline \multirow{2}{*}{ Contabilidad } & Egreso & $61.1 \%$ & $64.3 \%$ & $54.8 \%$ & $73.8 \%$ & $91.3 \%$ & $69.0 \%$ \\
\hline & Seguimiento & $63.1 \%$ & $63.1 \%$ & $95.2 \%$ & $92.9 \%$ & $98.8 \%$ & $82.6 \%$ \\
\hline \multirow{2}{*}{$\begin{array}{l}\text { Ingeniería } \\
\text { Eléctrica }\end{array}$} & Egreso & $50.8 \%$ & $75.0 \%$ & $63.7 \%$ & $84.7 \%$ & $91.1 \%$ & $73.1 \%$ \\
\hline & Seguimiento & $65.1 \%$ & $84.1 \%$ & $96.8 \%$ & $84.1 \%$ & $98.4 \%$ & $85.7 \%$ \\
\hline \multirow{2}{*}{$\begin{array}{l}\text { Ingeniería } \\
\text { Civil }\end{array}$} & Egreso & $57.7 \%$ & $76.2 \%$ & $59.2 \%$ & $93.8 \%$ & $88.5 \%$ & $75.1 \%$ \\
\hline & Seguimiento & $73.1 \%$ & $79.1 \%$ & $85.1 \%$ & $97.0 \%$ & $98.5 \%$ & $86.6 \%$ \\
\hline \multirow{2}{*}{ Derecho } & Egreso & $46.6 \%$ & $58.6 \%$ & $53.4 \%$ & $50.0 \%$ & $82.8 \%$ & $58.3 \%$ \\
\hline & Seguimiento & $58.3 \%$ & $41.7 \%$ & $83.3 \%$ & $62.5 \%$ & $100 \%$ & $69.2 \%$ \\
\hline \multirow{2}{*}{ Diseño Grafico } & Egreso & $58.3 \%$ & $50.0 \%$ & $58.3 \%$ & $58.3 \%$ & $83.3 \%$ & $61.7 \%$ \\
\hline & Seguimiento & $46.7 \%$ & $80.0 \%$ & $66.7 \%$ & $70.0 \%$ & $96.7 \%$ & $72.0 \%$ \\
\hline \multirow{2}{*}{$\begin{array}{l}\text { Ingeniería } \\
\text { en Sistemas } \\
\text { Digitales y Co- } \\
\text { municaciones }\end{array}$} & Egreso & $42.9 \%$ & $76.2 \%$ & $69.0 \%$ & $75.4 \%$ & $91.3 \%$ & $71.0 \%$ \\
\hline & Seguimiento & $56.4 \%$ & $75.5 \%$ & $84.5 \%$ & $85.5 \%$ & $99.1 \%$ & $80.2 \%$ \\
\hline \multirow{2}{*}{ Turismo } & Egreso & $59.4 \%$ & $56.3 \%$ & $50.0 \%$ & $37.5 \%$ & $90.6 \%$ & $58.8 \%$ \\
\hline & Seguimiento & $63.3 \%$ & $43.3 \%$ & $90.0 \%$ & $46.7 \%$ & $93.3 \%$ & $67.3 \%$ \\
\hline \multirow{2}{*}{$\begin{array}{l}\text { Adminis- } \\
\text { tración de } \\
\text { Empresas }\end{array}$} & Egreso & $58.0 \%$ & $63.8 \%$ & $65.5 \%$ & $76.1 \%$ & $84.6 \%$ & $69.6 \%$ \\
\hline & Seguimiento & $60.2 \%$ & $61.5 \%$ & $86.0 \%$ & $91.4 \%$ & $95.9 \%$ & $79.0 \%$ \\
\hline \multirow{2}{*}{ Arquitectura } & Egreso & $67.7 \%$ & $63.4 \%$ & $54.8 \%$ & $89.2 \%$ & $76.3 \%$ & $70.3 \%$ \\
\hline & Seguimiento & $62.1 \%$ & $73.5 \%$ & $72.7 \%$ & $88.6 \%$ & $92.4 \%$ & $77.9 \%$ \\
\hline \multirow{2}{*}{ Trabajo Social } & Egreso & $71.8 \%$ & $64.1 \%$ & $25.6 \%$ & $28.2 \%$ & $100 \%$ & $57.9 \%$ \\
\hline & Seguimiento & $34.5 \%$ & $44.8 \%$ & $82.8 \%$ & $62.1 \%$ & $100 \%$ & $64.8 \%$ \\
\hline \multirow{2}{*}{$\begin{array}{l}\text { Ingeniería en } \\
\text { Manufactura }\end{array}$} & Egreso & $52.3 \%$ & $77.1 \%$ & $80.4 \%$ & $79.1 \%$ & $89.5 \%$ & $75.7 \%$ \\
\hline & Seguimiento & $56.0 \%$ & $75.8 \%$ & $87.9 \%$ & $89.0 \%$ & $98.9 \%$ & $81.5 \%$ \\
\hline \multirow{2}{*}{ Psicología } & Egreso & $51.7 \%$ & $55.2 \%$ & $69.0 \%$ & $62.1 \%$ & $86.2 \%$ & $64.8 \%$ \\
\hline & Seguimiento & $53.8 \%$ & $56.4 \%$ & $76.9 \%$ & $61.5 \%$ & $94.9 \%$ & $68.7 \%$ \\
\hline \multirow{2}{*}{ Educación } & Egreso & $66.7 \%$ & $77.8 \%$ & $22.2 \%$ & $47.2 \%$ & $97.2 \%$ & $62.2 \%$ \\
\hline & Seguimiento & $63.2 \%$ & $52.6 \%$ & $89.5 \%$ & $26.3 \%$ & $94.7 \%$ & $65.3 \%$ \\
\hline \multirow{2}{*}{ Economía } & Egreso & $48.0 \%$ & $52.0 \%$ & $48.0 \%$ & $36.0 \%$ & $84.0 \%$ & $53.6 \%$ \\
\hline & Seguimiento & $39.1 \%$ & $52.2 \%$ & $65.2 \%$ & $47.8 \%$ & $69.6 \%$ & $54.8 \%$ \\
\hline \multirow{2}{*}{ Nutrición } & Egreso & $88.9 \%$ & $77.8 \%$ & $33.3 \%$ & $77.8 \%$ & $88.9 \%$ & $73.3 \%$ \\
\hline & Seguimiento & $40.9 \%$ & $81.8 \%$ & $68.2 \%$ & $77.3 \%$ & $100 \%$ & $73.6 \%$ \\
\hline \multirow{2}{*}{$\begin{array}{l}\text { Diseño de } \\
\text { interiores }\end{array}$} & Egreso & $84.6 \%$ & $76.9 \%$ & $30.8 \%$ & $84.6 \%$ & $84.6 \%$ & $72.3 \%$ \\
\hline & Seguimiento & $50.0 \%$ & $65.0 \%$ & $65.0 \%$ & $75.0 \%$ & $95.0 \%$ & $70.0 \%$ \\
\hline \multirow{2}{*}{ Sociología } & Egreso & $87.5 \%$ & $25.0 \%$ & $87.5 \%$ & $25.0 \%$ & $75.0 \%$ & $60.0 \%$ \\
\hline & Seguimiento & $50.0 \%$ & $50.0 \%$ & $50.0 \%$ & $16.7 \%$ & $100 \%$ & $53.3 \%$ \\
\hline \multirow{2}{*}{ Total } & Egreso & $58.69 \%$ & $65.56 \%$ & $53.98 \%$ & $64.72 \%$ & $86.70 \%$ & \\
\hline & Seguimiento & $60.5 \%$ & $68.39 \%$ & $80.58 \%$ & $75.66 \%$ & $96.32 \%$ & \\
\hline
\end{tabular}

Fuente: Elaboración propia. 
La tabla 1. revela que en el PE el 58.69\% tiene un nivel de ingreso de 1 a 6 SM y dos años después llega al 60.5\%, asumiendo 7 SM o más para PS. En el caso del tipo de puesto en el PE, el $65.56 \%$ se colocó en puestos que se consideran profesionales y dos años después el 68.39\% (PS). El grado educativo (vinculación) muestra que para el PE el 53.98\% de los egresados se colocaron en puestos donde no se encuentran sobrevalorados, es decir, que tienen empleos que sí requieren educación profesional. Para el PS aumenta a $80.58 \%$. La coincidencia del programa educativo estudiado y el empleo en el PE es de 64.72\%; obtuvieron un empleo que está muy relacionado con lo que estudiaron, y para el PS ese porcentaje aumenta a $75.66 \%$. Finalmente, para la coincidencia entre los conocimientos adquiridos en el programa y su empleo del PE, fue de $86.7 \%$ los tienen un empleo en donde aplican bastante los conocimientos adquiridos en su formación profesional, y el PS aumenta a 96.32\%. El aumento de todos los porcentajes indica que los egresados y programas participantes del mercado industrial mejoran su desempeño segmentándose en dos años. En contraste, se observa que los programas de diseño de interiores y sociología probablemente no logran segmentarse tan rápidamente.

La tabla 2. presenta de manera similar la información del IDL y sus componentes dentro del mercado de servicios y comercio (31 programas).

Tabla 2. Índice de Desempeño Laboral para el mercado de servicios y comercio.

\begin{tabular}{|c|c|c|c|c|c|c|c|}
\hline $\begin{array}{l}\text { Programa } \\
\text { Educativo }\end{array}$ & $\begin{array}{c}\text { Tipo de } \\
\text { Encuesta }\end{array}$ & $\begin{array}{c}\text { Nivel } \\
\text { Salarial }\end{array}$ & $\begin{array}{l}\text { Tipo de } \\
\text { Puesto }\end{array}$ & $\begin{array}{l}\text { Vincu- } \\
\text { lación }\end{array}$ & $\begin{array}{c}\text { Coincidencia } \\
\text { Programa/ } \\
\text { Empleo }\end{array}$ & $\begin{array}{c}\text { Coincidencia } \\
\text { Conocimien- } \\
\text { to/Empleo }\end{array}$ & IDL \\
\hline \multirow{2}{*}{$\begin{array}{l}\text { Médico } \\
\text { Cirujano }\end{array}$} & Egreso & $73.9 \%$ & $68.6 \%$ & $35.2 \%$ & $40.1 \%$ & $65.9 \%$ & $56.7 \%$ \\
\hline & Seguimiento & $87.5 \%$ & $100 \%$ & $50.0 \%$ & $87.5 \%$ & $100 \%$ & $85.0 \%$ \\
\hline \multirow{2}{*}{ Optometría } & Egreso & $66.7 \%$ & $55.6 \%$ & $44.4 \%$ & $55.6 \%$ & $66.7 \%$ & $66.4 \%$ \\
\hline & Seguimiento & $66.7 \%$ & $66.7 \%$ & $100 \%$ & $66.7 \%$ & $100 \%$ & $80.0 \%$ \\
\hline \multirow{2}{*}{$\begin{array}{l}\text { Ingeniería } \\
\text { Eléctrica }\end{array}$} & Egreso & $57.9 \%$ & $65.8 \%$ & $63.2 \%$ & $52.6 \%$ & $78.9 \%$ & $63.7 \%$ \\
\hline & Seguimiento & $66.7 \%$ & $79.2 \%$ & $95.8 \%$ & $87.5 \%$ & $100 \%$ & $85.8 \%$ \\
\hline \multirow{2}{*}{$\begin{array}{l}\text { Diseño } \\
\text { Industrial }\end{array}$} & Egreso & $70.4 \%$ & $63.0 \%$ & $33.3 \%$ & $48.1 \%$ & $85.2 \%$ & $60.0 \%$ \\
\hline & Seguimiento & $68.8 \%$ & $81.3 \%$ & $81.3 \%$ & $75.0 \%$ & $93.8 \%$ & $80.0 \%$ \\
\hline \multirow{2}{*}{$\begin{array}{l}\text { Entrenamiento } \\
\text { deportivo }\end{array}$} & Egreso & $77.1 \%$ & $68.6 \%$ & $34.3 \%$ & $28.6 \%$ & $91.4 \%$ & $60.0 \%$ \\
\hline & Seguimiento & $55.0 \%$ & $85.0 \%$ & $80.0 \%$ & $80.0 \%$ & $100 \%$ & $80.0 \%$ \\
\hline \multirow{2}{*}{ Arquitectura } & Egreso & $64.1 \%$ & $52.6 \%$ & $50.0 \%$ & $60.3 \%$ & $82.1 \%$ & $61.8 \%$ \\
\hline & Seguimiento & $67.5 \%$ & $82.5 \%$ & $77.5 \%$ & $85.0 \%$ & $90.0 \%$ & $80.5 \%$ \\
\hline \multirow{2}{*}{ Ingeniería Civil } & Egreso & $58.8 \%$ & $79.4 \%$ & $41.2 \%$ & $44.1 \%$ & $88.2 \%$ & $62.4 \%$ \\
\hline & Seguimiento & $64.7 \%$ & $88.2 \%$ & $76.5 \%$ & $70.6 \%$ & $100 \%$ & $80.0 \%$ \\
\hline \multirow{2}{*}{$\begin{array}{l}\text { Ingeniería en } \\
\text { Mecatrónica }\end{array}$} & Egreso & $66.7 \%$ & $69.7 \%$ & $39.4 \%$ & $45.5 \%$ & $84.8 \%$ & $61.2 \%$ \\
\hline & Seguimiento & $66.7 \%$ & $85.7 \%$ & $81.0 \%$ & $61.9 \%$ & $95.2 \%$ & $78.1 \%$ \\
\hline \multirow{2}{*}{$\begin{array}{l}\text { Ingeniería } \\
\text { Industrial y } \\
\text { de Sistemas }\end{array}$} & Egreso & $57.3 \%$ & $76.0 \%$ & $41.3 \%$ & $58.7 \%$ & $89.3 \%$ & $64.5 \%$ \\
\hline & Seguimiento & $69.4 \%$ & $69.4 \%$ & $83.3 \%$ & $80.6 \%$ & $100 \%$ & $80.6 \%$ \\
\hline
\end{tabular}


Víctor V. Ibáñez / Revista de la Educación Superior 48 (190) (2019) 113-137

\begin{tabular}{|c|c|c|c|c|c|c|c|}
\hline $\begin{array}{l}\text { Programa } \\
\text { Educativo }\end{array}$ & $\begin{array}{l}\text { Tipo de En- } \\
\text { cuesta }\end{array}$ & $\begin{array}{c}\text { Nivel } \\
\text { Salarial }\end{array}$ & $\begin{array}{l}\text { Tipo de } \\
\text { Puesto }\end{array}$ & $\begin{array}{l}\text { Vincu- } \\
\text { lación }\end{array}$ & $\begin{array}{c}\text { Coincidencia } \\
\text { Programa/ } \\
\text { Empleo }\end{array}$ & $\begin{array}{l}\text { Coincidencia } \\
\text { Conocimien- } \\
\text { to/Empleo }\end{array}$ & IDL \\
\hline \multirow{2}{*}{$\begin{array}{l}\text { Ingeniería } \\
\text { en Sistemas } \\
\text { Digitales y Co- } \\
\text { municaciones }\end{array}$} & Egreso & $61.4 \%$ & $72.9 \%$ & $55.7 \%$ & $60.0 \%$ & $90.0 \%$ & $68.0 \%$ \\
\hline & Seguimiento & $63.2 \%$ & $84.2 \%$ & $84.2 \%$ & $86.8 \%$ & $97.4 \%$ & $83.2 \%$ \\
\hline \multirow{2}{*}{$\begin{array}{l}\text { Ingeniería en } \\
\text { Sistemas Com- } \\
\text { putacionales }\end{array}$} & Egreso & $66.0 \%$ & $67.0 \%$ & $50.9 \%$ & $68.9 \%$ & $93.4 \%$ & $69.2 \%$ \\
\hline & Seguimiento & $62.7 \%$ & $78.7 \%$ & $84.0 \%$ & $89.3 \%$ & $98.7 \%$ & $82.7 \%$ \\
\hline \multirow{2}{*}{ Química } & Egreso & $66.7 \%$ & $58.3 \%$ & $41.7 \%$ & $66.7 \%$ & $100 \%$ & $66.7 \%$ \\
\hline & Seguimiento & $57.1 \%$ & $85.7 \%$ & $71.4 \%$ & $85.7 \%$ & $100 \%$ & $80.0 \%$ \\
\hline \multirow{2}{*}{ Enfermería } & Egreso & $89.7 \%$ & $88.7 \%$ & $19.6 \%$ & $17.5 \%$ & $94.8 \%$ & $62.1 \%$ \\
\hline & Seguimiento & $46.7 \%$ & $73.3 \%$ & $86.7 \%$ & $70.0 \%$ & $100 \%$ & $75.3 \%$ \\
\hline \multirow{2}{*}{ Educación } & Egreso & $85.7 \%$ & $69.6 \%$ & $20.5 \%$ & $24.1 \%$ & $93.8 \%$ & $58.8 \%$ \\
\hline & Seguimiento & $45.0 \%$ & $65.0 \%$ & $100 \%$ & $50.0 \%$ & $95.0 \%$ & $71.0 \%$ \\
\hline \multirow{2}{*}{ Odontología } & Egreso & $67.6 \%$ & $58.8 \%$ & $38.2 \%$ & $29.4 \%$ & $88.2 \%$ & $56.5 \%$ \\
\hline & Seguimiento & $46.2 \%$ & $71.8 \%$ & $84.6 \%$ & $74.4 \%$ & $100 \%$ & $75.4 \%$ \\
\hline \multirow{2}{*}{ Biología } & Egreso & $48.0 \%$ & $52.0 \%$ & $48.0 \%$ & $36.0 \%$ & $84.0 \%$ & $53.6 \%$ \\
\hline & Seguimiento & $73.7 \%$ & $36.8 \%$ & $73.7 \%$ & $57.9 \%$ & $100 \%$ & $68.4 \%$ \\
\hline \multirow{2}{*}{ Contabilidad } & Egreso & $66.3 \%$ & $85.3 \%$ & $39.0 \%$ & $83.4 \%$ & $91.9 \%$ & $73.2 \%$ \\
\hline & Seguimiento & $65.9 \%$ & $73.2 \%$ & $91.9 \%$ & $93.5 \%$ & $98.4 \%$ & $84.6 \%$ \\
\hline \multirow{2}{*}{ Psicología } & Egreso & $81.7 \%$ & $69.7 \%$ & $43.1 \%$ & $38.5 \%$ & $86.2 \%$ & $63.9 \%$ \\
\hline & Seguimiento & $55.3 \%$ & $71.8 \%$ & $76.7 \%$ & $72.8 \%$ & $96.1 \%$ & $74.6 \%$ \\
\hline \multirow{2}{*}{$\begin{array}{l}\text { Administración } \\
\text { de Empresas }\end{array}$} & Egreso & $62.5 \%$ & $75.5 \%$ & $43.2 \%$ & $77.3 \%$ & $87.5 \%$ & $69.2 \%$ \\
\hline & Seguimiento & $63.7 \%$ & $64.5 \%$ & $88.8 \%$ & $89.2 \%$ & $97.3 \%$ & $80.7 \%$ \\
\hline \multirow{2}{*}{ Diseño Grafico } & Egreso & $83.1 \%$ & $65.5 \%$ & $43.2 \%$ & $66.2 \%$ & $76.4 \%$ & $66.9 \%$ \\
\hline & Seguimiento & $42.1 \%$ & $86.5 \%$ & $77.4 \%$ & $83.5 \%$ & $95.5 \%$ & $77.0 \%$ \\
\hline \multirow{2}{*}{$\begin{array}{l}\text { Médico } \\
\text { Veterinario } \\
\text { Zootecnista }\end{array}$} & Egreso & $87.1 \%$ & $77.4 \%$ & $32.3 \%$ & $74.2 \%$ & $87.1 \%$ & $71.6 \%$ \\
\hline & Seguimiento & $35.7 \%$ & $82.1 \%$ & $85.7 \%$ & $100 \%$ & $96.4 \%$ & $80.0 \%$ \\
\hline \multirow{2}{*}{ Turismo } & Egreso & $80.7 \%$ & $74.5 \%$ & $39.6 \%$ & $59.4 \%$ & $86.5 \%$ & $68.1 \%$ \\
\hline & Seguimiento & $58.3 \%$ & $64.6 \%$ & $86.3 \%$ & $69.1 \%$ & $96.6 \%$ & $75.0 \%$ \\
\hline \multirow{2}{*}{$\begin{array}{l}\text { Diseño de } \\
\text { interiores }\end{array}$} & Egreso & $94.4 \%$ & $75.0 \%$ & $44.4 \%$ & $47.2 \%$ & $80.6 \%$ & $68.3 \%$ \\
\hline & Seguimiento & $55.6 \%$ & $66.7 \%$ & $75.6 \%$ & $84.4 \%$ & $88.9 \%$ & $74.2 \%$ \\
\hline \multirow{2}{*}{ Derecho } & Egreso & $68.2 \%$ & $70.8 \%$ & $54.3 \%$ & $73.7 \%$ & $89.6 \%$ & $71.3 \%$ \\
\hline & Seguimiento & $55.2 \%$ & $79.2 \%$ & $79.2 \%$ & $84.9 \%$ & $86.9 \%$ & $77.1 \%$ \\
\hline \multirow{2}{*}{ Nutrición } & Egreso & $83.0 \%$ & $74.5 \%$ & $19.1 \%$ & $36.2 \%$ & $95.7 \%$ & $61.7 \%$ \\
\hline & Seguimiento & $35.1 \%$ & $67.6 \%$ & $78.4 \%$ & $56.8 \%$ & $97.3 \%$ & $67.0 \%$ \\
\hline \multirow{2}{*}{ Sociología } & Egreso & $82.4 \%$ & $70.6 \%$ & $17.6 \%$ & $47.1 \%$ & $100 \%$ & $63.5 \%$ \\
\hline & Seguimiento & $61.5 \%$ & $53.8 \%$ & $76.9 \%$ & $46.2 \%$ & $100 \%$ & $67.7 \%$ \\
\hline \multirow{2}{*}{ Trabajo Social } & Egreso & $90.3 \%$ & $66.7 \%$ & $33.3 \%$ & $40.3 \%$ & $97.2 \%$ & $65.6 \%$ \\
\hline & Seguimiento & $53.0 \%$ & $54.5 \%$ & $83.3 \%$ & $54.5 \%$ & $98.5 \%$ & $68.8 \%$ \\
\hline \multirow{2}{*}{$\begin{array}{l}\text { Ingeniería en } \\
\text { Manufactura }\end{array}$} & Egreso & $76.9 \%$ & $92.3 \%$ & $61.5 \%$ & $53.8 \%$ & $100 \%$ & $76.9 \%$ \\
\hline & Seguimiento & $71.4 \%$ & $85.7 \%$ & $71.4 \%$ & $57.1 \%$ & $100 \%$ & $77.1 \%$ \\
\hline \multirow{2}{*}{ Economía } & Egreso & $67.8 \%$ & $64.4 \%$ & $37.3 \%$ & $67.8 \%$ & $93.2 \%$ & $66.1 \%$ \\
\hline & Seguimiento & $56.8 \%$ & $64.9 \%$ & $64.9 \%$ & $64.9 \%$ & $78.4 \%$ & $65.9 \%$ \\
\hline
\end{tabular}




\begin{tabular}{llcccccc}
\hline $\begin{array}{c}\text { Programa } \\
\text { Educativo }\end{array}$ & $\begin{array}{c}\text { Tipo de En- } \\
\text { cuesta }\end{array}$ & $\begin{array}{c}\text { Nivel } \\
\text { Salarial }\end{array}$ & $\begin{array}{c}\text { Tipo de } \\
\text { Puesto }\end{array}$ & $\begin{array}{c}\text { Vincu- } \\
\text { lación }\end{array}$ & $\begin{array}{c}\text { Coincidencia Coincidencia } \\
\text { Programa/ } \\
\text { Empleo }\end{array}$ & $\begin{array}{c}\text { Conocimien- } \\
\text { to/Empleo }\end{array}$ & IDL \\
\hline \multirow{2}{*}{ Mercadotecnia } & Egreso & $92.0 \%$ & $80.0 \%$ & $32.0 \%$ & $72.0 \%$ & $88.0 \%$ & $72.8 \%$ \\
\cline { 2 - 8 } & Seguimiento & $34.4 \%$ & $46.9 \%$ & $81.3 \%$ & $81.3 \%$ & $100 \%$ & $68.8 \%$ \\
\hline \multirow{2}{*}{ Artes Visuales } & Egreso & $80.0 \%$ & $60.0 \%$ & $45.0 \%$ & $65.0 \%$ & $90.0 \%$ & $68.0 \%$ \\
\cline { 2 - 8 } & Seguimiento & $60.0 \%$ & $70.0 \%$ & $50.0 \%$ & $40.0 \%$ & $80.0 \%$ & $60.0 \%$ \\
\hline \multirow{2}{*}{ Total } & Egreso & $\mathbf{7 4 . 4 0} \%$ & $\mathbf{7 0 . 7 0} \%$ & $\mathbf{3 9 . 6 5 \%}$ & $\mathbf{5 2 . 6 9 \%}$ & $\mathbf{8 8 . 3 1 \%}$ & \\
\cline { 2 - 8 } & Seguimiento & $\mathbf{5 8 . 4 3} \%$ & $\mathbf{7 3 . 0 8 \%}$ & $\mathbf{7 9 . 9 2} \%$ & $\mathbf{7 3 . 7 8} \%$ & $\mathbf{9 6 . 1 4} \%$ & \\
\hline
\end{tabular}

Fuente: Elaboración propia.

En el PE el 74.4\% tiene un nivel salarial de 1 a 6 SM y para el PS el 58.43\% tienen un nivel salarial de 7 SM o más; esto podría indicar que dos años no es el tiempo suficiente para notar un cambio en la segmentación de los egresados dentro del mercado de servicios y comercio. Resulta interesante este dato, pues se ajusta más o menos a lo que algunas teorías de mercados laborales presentan. El mercado industrial históricamente es el que provee mayores salarios y condiciones laborales respecto a otros tipos de mercado. Para el caso del tipo de puesto en el padrón de egreso, el 70.7\% se colocó en puestos que se consideran profesionales y dos años después el 73.08\%. El grado educativo (vinculación) muestra para el PE el 39.65\%; se colocaron en puestos donde no se encuentran sobrevalorados. Tienen empleos los cuales sí requieren educación profesional, para el PS aumenta a 79.92\%. La coincidencia del programa educativo y el empleo en el PE resultó en 52.69\%, lo que indica que está muy relacionado con lo que estudiaron. Para el PS ese porcentaje aumenta a $73.78 \%$. Finalmente, para la coincidencia entre los conocimientos adquiridos y su empleo se situó en 88.31 \% PE, que implica un empleo en donde aplican bastante los conocimientos en su formación profesional y el PS se incrementa a $96.14 \%$. Se asume que haya un aumento en los porcentajes podría indicar que los programas que están dentro de este mercado mejoran al segmentarse, al menos en dos años. Un efecto contrario, se observa que los programas de economía y mercadotecnia, en comparación con los demás programas educativos dentro del mercado de servicios y comercio, lo cual sugiere que al paso de dos años no es tiempo suficiente para notar un cambio en la segmentación dentro del mercado.

La tabla 3. presenta la información del IDL de los programas educativos dentro del mercado de educación (27 programas). 
Víctor V. Ibáñez / Revista de la Educación Superior 48 (190) (2019) 113-137

Tabla 3. Índice de Desempeño Laboral para el mercado de educación.

\begin{tabular}{|c|c|c|c|c|c|c|c|}
\hline $\begin{array}{l}\text { Programa } \\
\text { Educativo }\end{array}$ & $\begin{array}{c}\text { Tipo de } \\
\text { Encuesta }\end{array}$ & $\begin{array}{c}\text { Nivel } \\
\text { Salarial }\end{array}$ & $\begin{array}{l}\text { Tipo de } \\
\text { Puesto }\end{array}$ & $\begin{array}{l}\text { Vincu- } \\
\text { lación }\end{array}$ & $\begin{array}{c}\text { Coincidencia } \\
\text { Programa/ } \\
\text { Empleo }\end{array}$ & $\begin{array}{c}\text { Coincidencia } \\
\text { Conocimien- } \\
\text { to/Empleo }\end{array}$ & IDL \\
\hline \multirow{2}{*}{ Médico Cirujano } & Egreso & $86.8 \%$ & $66.0 \%$ & $34.0 \%$ & $52.8 \%$ & $86.8 \%$ & $65.3 \%$ \\
\hline & Seguimiento & $83.3 \%$ & $100 \%$ & $66.7 \%$ & $100 \%$ & $100 \%$ & $90.0 \%$ \\
\hline \multirow{2}{*}{$\begin{array}{l}\text { Ingeniería } \\
\text { Industrial y } \\
\text { de Sistemas }\end{array}$} & Egreso & $73.5 \%$ & $67.6 \%$ & $47.1 \%$ & $52.9 \%$ & $85.3 \%$ & $65.3 \%$ \\
\hline & Seguimiento & $47.6 \%$ & $85.7 \%$ & $85.7 \%$ & $81.0 \%$ & $100 \%$ & $80.0 \%$ \\
\hline \multirow{2}{*}{ Artes Visuales } & Egreso & $88.9 \%$ & $77.8 \%$ & $11.1 \%$ & $77.8 \%$ & $88.9 \%$ & $68.9 \%$ \\
\hline & Seguimiento & $38.5 \%$ & $100 \%$ & $76.9 \%$ & $100 \%$ & $100 \%$ & $83.1 \%$ \\
\hline \multirow{2}{*}{$\begin{array}{l}\text { Ingeniería en } \\
\text { Sistemas Com- } \\
\text { putacionales }\end{array}$} & Egreso & $74.7 \%$ & $53.3 \%$ & $57.3 \%$ & $77.3 \%$ & $80.0 \%$ & $68.5 \%$ \\
\hline & Seguimiento & $60.5 \%$ & $84.2 \%$ & $78.9 \%$ & $86.8 \%$ & $97.4 \%$ & $81.6 \%$ \\
\hline \multirow{2}{*}{ Nutrición } & Egreso & $93.3 \%$ & $60.0 \%$ & $46.7 \%$ & $46.7 \%$ & $93.3 \%$ & $68.0 \%$ \\
\hline & Seguimiento & $52.2 \%$ & $87.0 \%$ & $82.6 \%$ & $82.6 \%$ & $95.7 \%$ & $80.0 \%$ \\
\hline \multirow{2}{*}{$\begin{array}{l}\text { Ingeniería en } \\
\text { Sistemas Digita- } \\
\text { les y Comunica- } \\
\text { ciones }\end{array}$} & Egreso & $85.2 \%$ & $74.1 \%$ & $48.1 \%$ & $77.8 \%$ & $81.5 \%$ & $73.3 \%$ \\
\hline & Seguimiento & $64.0 \%$ & $80.0 \%$ & $88.0 \%$ & $96.0 \%$ & $96.0 \%$ & $84.8 \%$ \\
\hline \multirow{2}{*}{ Contabilidad } & Egreso & $78.9 \%$ & $71.1 \%$ & $31.6 \%$ & $52.6 \%$ & $89.5 \%$ & $64.7 \%$ \\
\hline & Seguimiento & $50.0 \%$ & $72.2 \%$ & $94.4 \%$ & $61.1 \%$ & $100 \%$ & $75.6 \%$ \\
\hline \multirow{2}{*}{$\begin{array}{l}\text { Ingeniería en } \\
\text { Mecatrónica }\end{array}$} & Egreso & $85.7 \%$ & $92.9 \%$ & $50.0 \%$ & $78.6 \%$ & $100 \%$ & $81.4 \%$ \\
\hline & Seguimiento & $90.0 \%$ & $90.0 \%$ & $100 \%$ & $80.0 \%$ & $100 \%$ & $92.0 \%$ \\
\hline \multirow{2}{*}{$\begin{array}{l}\text { Administración } \\
\text { de Empresas }\end{array}$} & Egreso & $87.5 \%$ & $80.0 \%$ & $35.0 \%$ & $77.5 \%$ & $83.8 \%$ & $72.8 \%$ \\
\hline & Seguimiento & $67.6 \%$ & $66.2 \%$ & $94.1 \%$ & $83.8 \%$ & $97.1 \%$ & $81.8 \%$ \\
\hline \multirow{2}{*}{ Turismo } & Egreso & $81.8 \%$ & $68.2 \%$ & $22.7 \%$ & $50.0 \%$ & $95.5 \%$ & $63.6 \%$ \\
\hline & Seguimiento & $42.1 \%$ & $73.7 \%$ & $94.7 \%$ & $47.4 \%$ & $100 \%$ & $71.6 \%$ \\
\hline \multirow{2}{*}{ Diseño Grafico } & Egreso & $85.3 \%$ & $64.7 \%$ & $41.2 \%$ & $76.5 \%$ & $91.2 \%$ & $71.8 \%$ \\
\hline & Seguimiento & $51.2 \%$ & $87.8 \%$ & $82.9 \%$ & $78.0 \%$ & $97.6 \%$ & $79.5 \%$ \\
\hline \multirow{2}{*}{ Trabajo Social } & Egreso & $91.1 \%$ & $75.6 \%$ & $35.6 \%$ & $82.2 \%$ & $86.7 \%$ & $74.2 \%$ \\
\hline & Seguimiento & $49.2 \%$ & $77.0 \%$ & $96.7 \%$ & $88.5 \%$ & $96.7 \%$ & $81.6 \%$ \\
\hline \multirow{2}{*}{ Psicología } & Egreso & $83.7 \%$ & $74.0 \%$ & $48.1 \%$ & $70.2 \%$ & $83.7 \%$ & $71.9 \%$ \\
\hline & Seguimiento & $44.8 \%$ & $79.0 \%$ & $81.9 \%$ & $92.4 \%$ & $98.1 \%$ & $79.2 \%$ \\
\hline \multirow{2}{*}{ Arquitectura } & Egreso & $87.5 \%$ & $50.0 \%$ & $31.3 \%$ & $50.0 \%$ & $75.0 \%$ & $58.8 \%$ \\
\hline & Seguimiento & $14.3 \%$ & $71.4 \%$ & $85.7 \%$ & $57.1 \%$ & $100 \%$ & $65.7 \%$ \\
\hline \multirow{2}{*}{ Educación } & Egreso & $94.5 \%$ & $79.8 \%$ & $45.9 \%$ & $77.5 \%$ & $83.1 \%$ & $76.2 \%$ \\
\hline & Seguimiento & $50.0 \%$ & $87.1 \%$ & $85.7 \%$ & $96.0 \%$ & $96.4 \%$ & $83.0 \%$ \\
\hline \multirow{2}{*}{ Biología } & Egreso & $86.7 \%$ & $46.7 \%$ & $60.0 \%$ & $73.3 \%$ & $80.0 \%$ & $69.3 \%$ \\
\hline & Seguimiento & $46.4 \%$ & $85.7 \%$ & $60.7 \%$ & $89.3 \%$ & $96.4 \%$ & $75.7 \%$ \\
\hline \multirow{2}{*}{ Ingeniería Física } & Egreso & $100 \%$ & $100 \%$ & $25.0 \%$ & $50.0 \%$ & $100 \%$ & $75.0 \%$ \\
\hline & Seguimiento & $33.3 \%$ & $88.9 \%$ & $88.9 \%$ & $88.9 \%$ & $100 \%$ & $80.0 \%$ \\
\hline \multirow{2}{*}{ Química } & Egreso & $95.7 \%$ & $82.6 \%$ & $39.1 \%$ & $78.3 \%$ & $87.0 \%$ & $76.5 \%$ \\
\hline & Seguimiento & $57.9 \%$ & $73.7 \%$ & $84.2 \%$ & $94.7 \%$ & $94.7 \%$ & $81.1 \%$ \\
\hline \multirow{2}{*}{ Economía } & Egreso & $88.0 \%$ & $72.0 \%$ & $12.0 \%$ & $64.0 \%$ & $92.0 \%$ & $65.6 \%$ \\
\hline & Seguimiento & $56.3 \%$ & $68.8 \%$ & $75.0 \%$ & $56.3 \%$ & $93.8 \%$ & $70.0 \%$ \\
\hline
\end{tabular}




\begin{tabular}{|c|c|c|c|c|c|c|c|}
\hline $\begin{array}{l}\text { Programa } \\
\text { Educativo }\end{array}$ & $\begin{array}{l}\text { Tipo de } \\
\text { Encuesta }\end{array}$ & $\begin{array}{c}\text { Nivel } \\
\text { Salarial }\end{array}$ & $\begin{array}{l}\text { Tipo de } \\
\text { Puesto }\end{array}$ & $\begin{array}{l}\text { Vincu- } \\
\text { lación }\end{array}$ & $\begin{array}{c}\text { Coincidencia } \\
\text { Programa/ } \\
\text { Empleo }\end{array}$ & $\begin{array}{l}\text { Coincidencia } \\
\text { Conocimien- } \\
\text { to/Empleo }\end{array}$ & IDL \\
\hline \multirow{2}{*}{ Sociología } & Egreso & $85.7 \%$ & $78.6 \%$ & $42.9 \%$ & $71.4 \%$ & $78.6 \%$ & $71.4 \%$ \\
\hline & Seguimiento & $50.0 \%$ & $87.5 \%$ & $62.5 \%$ & $87.5 \%$ & $87.5 \%$ & $75.0 \%$ \\
\hline \multirow{2}{*}{ Matemáticas } & Egreso & $90.0 \%$ & $60.0 \%$ & $50.0 \%$ & $86.7 \%$ & $90.0 \%$ & $75.3 \%$ \\
\hline & Seguimiento & $39.3 \%$ & $89.3 \%$ & $64.3 \%$ & $96.4 \%$ & $100 \%$ & $77.9 \%$ \\
\hline \multirow{2}{*}{ Derecho } & Egreso & $75.0 \%$ & $72.5 \%$ & $42.5 \%$ & $62.5 \%$ & $90.0 \%$ & $68.5 \%$ \\
\hline & Seguimiento & $40.5 \%$ & $64.3 \%$ & $71.4 \%$ & $76.2 \%$ & $92.9 \%$ & $69.0 \%$ \\
\hline \multirow{2}{*}{$\begin{array}{l}\text { Entrenamiento } \\
\text { deportivo }\end{array}$} & Egreso & $83.0 \%$ & $85.1 \%$ & $51.1 \%$ & $85.1 \%$ & $97.9 \%$ & $80.4 \%$ \\
\hline & Seguimiento & $43.5 \%$ & $71.0 \%$ & $89.9 \%$ & $88.4 \%$ & $100 \%$ & $78.6 \%$ \\
\hline \multirow{2}{*}{ Historia } & Egreso & $87.5 \%$ & $68.8 \%$ & $37.5 \%$ & $87.5 \%$ & $93.8 \%$ & $75.0 \%$ \\
\hline & Seguimiento & $17.6 \%$ & $76.5 \%$ & $76.5 \%$ & $94.1 \%$ & $94.1 \%$ & $71.8 \%$ \\
\hline \multirow{2}{*}{ Ingeniería Civil } & Egreso & $75.0 \%$ & $91.7 \%$ & $50.0 \%$ & $41.7 \%$ & $91.7 \%$ & $70.0 \%$ \\
\hline & Seguimiento & $50.0 \%$ & $33.3 \%$ & $83.3 \%$ & $66.7 \%$ & $100 \%$ & $66.7 \%$ \\
\hline \multirow{2}{*}{ Odontología } & Egreso & $86.7 \%$ & $73.3 \%$ & $46.7 \%$ & $33.3 \%$ & $86.7 \%$ & $65.3 \%$ \\
\hline & Seguimiento & $0.0 \%$ & $62.5 \%$ & $75.0 \%$ & $62.5 \%$ & $100 \%$ & $60.0 \%$ \\
\hline \multirow{2}{*}{$\begin{array}{l}\text { Diseño de } \\
\text { interiores }\end{array}$} & Egreso & $100 \%$ & $66.7 \%$ & $44.4 \%$ & $55.6 \%$ & $88.9 \%$ & $71.1 \%$ \\
\hline & Seguimiento & $14.3 \%$ & $71.4 \%$ & $57.1 \%$ & $57.1 \%$ & $85.7 \%$ & $57.1 \%$ \\
\hline \multirow{2}{*}{ Total } & Egreso & $86.35 \%$ & $72.33 \%$ & $40.25 \%$ & $66.29 \%$ & $88.16 \%$ & \\
\hline & Seguimiento & $46.46 \%$ & $78.31 \%$ & $80.89 \%$ & $81.07 \%$ & $97.03 \%$ & \\
\hline
\end{tabular}

Fuente: Elaboración propia.

El PE es de $86.5 \%$ (nivel salarial de 1 a 6 SM), para el PS disminuye a $46.46 \%$. Para el caso del tipo de puesto en el PE fue 72.33\% y el PS resultó en $78.31 \%$. El grado educativo (vinculación) muestra que para el PE es $40.25 \%$ que se colocaron en puestos donde no se encuentran sobrevalorados. El PS aumenta a $80.89 \%$. La coincidencia del programa educativo estudiado y el empleo para el PE fue $66.29 \%$. El PS su porcentaje aumenta a $81.07 \%$. Finalmente, para la coincidencia entre los conocimientos adquiridos en el programa y su empleo para el PE el $88.16 \%$ de los egresados tienen un empleo que utilizan bastante los conocimientos de su formación profesional y dos años después (PS) aumenta a $97.03 \%$. Este aumento sugiere que los programas que participan en el mercado mejoran su segmentación (desempeño) por lo menos a los dos años. Nuevamente, el IDL general por programa muestra que diseño de interiores, entrenamiento deportivo, historia, ingeniería civil y odontología no tienen un incremento en su desempeño y no logran segmentarse en este mercado con la misma rapidez que lo hacen los otros programas.

Por último, en la tabla 4, se presenta el IDL del mercado de salud (16 programas), así como la composición de sus subindicadores. 
Tabla 4. Índice de Desempeño Laboral para el mercado de salud.

\begin{tabular}{|c|c|c|c|c|c|c|c|}
\hline $\begin{array}{l}\text { Programa } \\
\text { Educativo }\end{array}$ & $\begin{array}{l}\text { Tipo de } \\
\text { Encuesta }\end{array}$ & $\begin{array}{c}\text { Nivel } \\
\text { Salarial }\end{array}$ & $\begin{array}{l}\text { Tipo de } \\
\text { Puesto }\end{array}$ & $\begin{array}{l}\text { Vincu- } \\
\text { lación }\end{array}$ & $\begin{array}{c}\text { Coincidencia } \\
\text { Programa/ } \\
\text { Empleo }\end{array}$ & $\begin{array}{l}\text { Coincidencia } \\
\text { Conocimien- } \\
\text { to/Empleo }\end{array}$ & IDL \\
\hline \multirow{2}{*}{ Psicología } & Egreso & $74.2 \%$ & $54.8 \%$ & $16.1 \%$ & $29.0 \%$ & $64.5 \%$ & $47.7 \%$ \\
\hline & Seguimiento & $35.5 \%$ & $64.5 \%$ & $77.4 \%$ & $61.3 \%$ & $100 \%$ & $67.7 \%$ \\
\hline \multirow{2}{*}{ Médico Cirujano } & Egreso & $70.8 \%$ & $64.2 \%$ & $41.5 \%$ & $74.5 \%$ & $84.0 \%$ & $67.0 \%$ \\
\hline & Seguimiento & $72.9 \%$ & $86.5 \%$ & $72.2 \%$ & $98.5 \%$ & $98.1 \%$ & $85.6 \%$ \\
\hline \multirow{2}{*}{$\begin{array}{l}\text { Médico Veterinario } \\
\text { Zootecnista }\end{array}$} & Egreso & $92.9 \%$ & $64.3 \%$ & $38.1 \%$ & $88.1 \%$ & $85.7 \%$ & $73.8 \%$ \\
\hline & Seguimiento & $52.9 \%$ & $94.1 \%$ & $92.6 \%$ & $100 \%$ & $97.1 \%$ & $87.4 \%$ \\
\hline \multirow{2}{*}{$\begin{array}{l}\text { Administración de } \\
\text { Empresas }\end{array}$} & Egreso & $61.5 \%$ & $69.2 \%$ & $48.7 \%$ & $59.0 \%$ & $87.2 \%$ & $65.1 \%$ \\
\hline & Seguimiento & $77.3 \%$ & $31.8 \%$ & $95.5 \%$ & $81.8 \%$ & $100 \%$ & $77.3 \%$ \\
\hline \multirow{2}{*}{ Odontología } & Egreso & $73.0 \%$ & $72.6 \%$ & $21.8 \%$ & $84.9 \%$ & $88.1 \%$ & $68.1 \%$ \\
\hline & Seguimiento & $40.7 \%$ & $76.3 \%$ & $85.0 \%$ & $96.4 \%$ & $97.6 \%$ & $79.2 \%$ \\
\hline \multirow{2}{*}{ Ingeniería Eléctrica } & Egreso & $77.8 \%$ & $55.6 \%$ & $66.7 \%$ & $77.8 \%$ & $66.7 \%$ & $68.9 \%$ \\
\hline & Seguimiento & $75.0 \%$ & $50.0 \%$ & $100 \%$ & $75.0 \%$ & $100 \%$ & $80.0 \%$ \\
\hline \multirow{2}{*}{ Optometría } & Egreso & $86.7 \%$ & $76.7 \%$ & $40.0 \%$ & $96.7 \%$ & $90.0 \%$ & $78.0 \%$ \\
\hline & Seguimiento & $64.3 \%$ & $75.0 \%$ & $96.4 \%$ & $96.4 \%$ & $100 \%$ & $86.4 \%$ \\
\hline \multirow{2}{*}{ Contabilidad } & Egreso & $81.3 \%$ & $56.3 \%$ & $31.3 \%$ & $81.3 \%$ & $87.5 \%$ & $67.5 \%$ \\
\hline & Seguimiento & $69.6 \%$ & $56.5 \%$ & $82.6 \%$ & $73.9 \%$ & $95.7 \%$ & $75.7 \%$ \\
\hline \multirow{2}{*}{ Turismo } & Egreso & $77.8 \%$ & $61.1 \%$ & $27.8 \%$ & $50.0 \%$ & $88.9 \%$ & $61.1 \%$ \\
\hline & Seguimiento & $88.9 \%$ & $66.7 \%$ & $66.7 \%$ & $33.3 \%$ & $88.9 \%$ & $68.9 \%$ \\
\hline \multirow{2}{*}{ Derecho } & Egreso & $67.6 \%$ & $61.8 \%$ & $61.8 \%$ & $41.2 \%$ & $85.3 \%$ & $63.5 \%$ \\
\hline & Seguimiento & $57.9 \%$ & $63.2 \%$ & $89.5 \%$ & $47.4 \%$ & $94.7 \%$ & $70.5 \%$ \\
\hline \multirow{2}{*}{ Enfermería } & Egreso & $79.5 \%$ & $60.7 \%$ & $55.4 \%$ & $89.3 \%$ & $91.1 \%$ & $75.2 \%$ \\
\hline & Seguimiento & $49.5 \%$ & $72.8 \%$ & $91.0 \%$ & $95.2 \%$ & $99.2 \%$ & $81.5 \%$ \\
\hline \multirow{2}{*}{$\begin{array}{l}\text { Ingeniería en } \\
\text { Sistemas Compu- } \\
\text { tacionales }\end{array}$} & Egreso & $40.0 \%$ & $80.0 \%$ & $46.7 \%$ & $80.0 \%$ & $93.3 \%$ & $68.0 \%$ \\
\hline & Seguimiento & $42.9 \%$ & $71.4 \%$ & $100 \%$ & $57.1 \%$ & $100 \%$ & $74.3 \%$ \\
\hline \multirow{2}{*}{ Química } & Egreso & $82.4 \%$ & $79.4 \%$ & $47.1 \%$ & $73.5 \%$ & $97.1 \%$ & $75.9 \%$ \\
\hline & Seguimiento & $67.4 \%$ & $80.4 \%$ & $71.7 \%$ & $89.1 \%$ & $100 \%$ & $81.7 \%$ \\
\hline \multirow{2}{*}{ Nutrición } & Egreso & $89.5 \%$ & $65.8 \%$ & $52.6 \%$ & $76.3 \%$ & $76.3 \%$ & $72.1 \%$ \\
\hline & Seguimiento & $52.5 \%$ & $89.1 \%$ & $71.3 \%$ & $83.2 \%$ & $87.1 \%$ & $76.6 \%$ \\
\hline \multirow{2}{*}{ Trabajo Social } & Egreso & $76.9 \%$ & $100 \%$ & $34.6 \%$ & $73.1 \%$ & $100 \%$ & $76.9 \%$ \\
\hline & Seguimiento & $60.8 \%$ & $80.4 \%$ & $78.4 \%$ & $90.2 \%$ & $96.1 \%$ & $81.2 \%$ \\
\hline \multirow{2}{*}{$\begin{array}{l}\text { Entrenamiento } \\
\text { deportivo }\end{array}$} & Egreso & $78.6 \%$ & $85.7 \%$ & $46.4 \%$ & $82.1 \%$ & $92.9 \%$ & $77.1 \%$ \\
\hline & Seguimiento & $50.0 \%$ & $81.3 \%$ & $68.8 \%$ & $87.5 \%$ & $87.5 \%$ & $75.0 \%$ \\
\hline \multirow{2}{*}{ Total } & Egreso & $75.64 \%$ & $69.26 \%$ & $42.28 \%$ & $72.30 \%$ & $86.15 \%$ & \\
\hline & Seguimiento & $59.87 \%$ & $71.25 \%$ & $83.70 \%$ & $79.15 \%$ & $96.37 \%$ & \\
\hline
\end{tabular}

Fuente: Elaboración propia.

En el PE respecto al salario quedó en $75.4 \%$ para niveles salariales de 1 a 6 . El PS se reduce al 59.87\% (nivel salarial de 7 SM o más). En correspondencia al mercado de educación, el de la salud nos sugiere que dos años no son tiempo suficiente para notar un cambio en el desempeño en el mercado de salud. 
Otra explicación puede ser la saturación en cuanto a los puestos de trabajo para esta oferta laboral. En el caso del tipo de puesto el PE se ubica en $69.26 \%$, que sugieren puestos considerados profesionales y para el PS el 71.25\%. El grado educativo (vinculación) muestra que para el PE el $42.28 \%$ de ellos se colocaron en puestos donde no se encuentran sobrevalorados. El PS aumenta a $83.7 \%$. La coincidencia del programa educativo estudiado y el empleo para el PE deduce que el $72.3 \%$ obtuvieron un empleo que está muy relacionado con lo que estudiaron. Para el PS esa relación relativa aumenta a 79.15\%. Referente a la coincidencia entre los conocimientos y su empleo el PE señala que un $86.15 \%$ de los egresados tienen un empleo en donde aplican bastante los conocimientos, siendo el PS un efecto mayor en $96.37 \%$.

\section{El Modelo empírico, una comprobación de la segmentación de los egresados y programas educativos de los mercados en estudio.}

Con los IDL calculados por programa educativo en cada mercado, se pone a prueba una segunda propuesta metodológica, que consiste en estimar los 4 mercados que utilizan como variable dependientes el crecimiento en el cambio relativo del PS respecto al PE del periodo establecido. Se presenta la variable a explicar en la ecuación (2).

Ecuación 2. Cambio en IDL

El modelo también considera como variable independiente un efecto exógeno (en este caso cómo la crisis financiera del 2008 al 2010 pudo influir en el desempeño de los egresados que se colocan en los diferentes mercados de trabajo), construyendo una variable dummy=1 para los años 2008, 2009 y 2010, cero para los demás. Las otras variables independientes serán los programas educativos que tiene cada sector, considerando cada programa una variable dummy. El modelo econométrico general se define con la ecuación 3.

\section{Ecuación 3. Modelo Econométrico Genera}

Donde:

$\triangle I D L j 4=$ Es el cambio relativo de los índices de desempeño al momento de egresar y dos años después para los programas en los 4 mercados de estudios de manera individual. 
Prog $\mathrm{X}=$ Variable dummy que implica al programa educativo que se selecciona. $D C F=$ Variable dummy que implica la época de crisis financiera $=1(2008,2009$ y 2010), cero $=$ Cualquier año diferente a los anteriores.

$=$ son los estimadores convencionales de un modelo de regresión lineal $\varepsilon i=$ Es el término de error.

El modelo econométrico se realiza en Stata versión 12. Cabe mencionar que por problemas de heteroscedasticidad en algunos mercados, se corre un modelo robusto a través de la prueba Breusch-Pagan, hettest. A continuación, se muestran los resultados de los modelos econométricos para cada mercado.

Tabla 5. Estimaciones de los mercados en estudio

\begin{tabular}{|c|c|c|c|c|}
\hline $\begin{array}{l}\text { Programa } \\
\text { Educativo }\end{array}$ & $\begin{array}{c}\text { Mercado } \\
\text { Industrial }\end{array}$ & $\begin{array}{l}\text { Mercado } \\
\text { Servicios y } \\
\text { Comercio }\end{array}$ & $\begin{array}{c}\text { Mercado } \\
\text { Educación }\end{array}$ & Mercado Salud \\
\hline $\begin{array}{l}\text { Administración de } \\
\text { Empresas }\end{array}$ & $0.5060^{\star * *}$ & $0.6168^{* * *}$ & 0.3586 & $0.4270^{*}$ \\
\hline Arquitectura & $0.4551^{* *}$ & $0.7267^{* * *}$ & 0.0888 & \\
\hline Artes Visuales & & & $0.6430^{* *}$ & \\
\hline Biología & & $0.6887^{* * *}$ & $0.5344^{* *}$ & \\
\hline Contabilidad & $0.6353^{* * *}$ & $0.6413^{* * *}$ & 0.3945 & $0.6244^{* * *}$ \\
\hline Derecho & 0.2892 & $0.5344^{* * *}$ & 0.3235 & 0.2741 \\
\hline Diseño de interiores & $0.4482^{*}$ & $0.5910^{* * *}$ & -0.0670 & \\
\hline Diseño Grafico & $0.5607^{* * *}$ & $0.5821^{* * *}$ & 0.3071 & \\
\hline Diseño Industrial & $0.7577^{* * *}$ & $0.7878^{* *}$ & & \\
\hline Economía & 0.3944 & $0.5557^{* * *}$ & $0.4674^{*}$ & \\
\hline Educación & & 0.3695 & 0.3477 & \\
\hline Enfermería & 0.4074 & $0.4668^{* *}$ & & $0.5013^{* *}$ \\
\hline $\begin{array}{l}\text { Entrenamiento } \\
\text { deportivo }\end{array}$ & & $0.7384^{* * *}$ & 0.2183 & 0.1411 \\
\hline Ingeniería Civil & $0.5403^{* * *}$ & $0.7356^{* * *}$ & -0.0638 & \\
\hline Ingeniería Eléctrica & $0.5753^{\star * *}$ & $0.9220^{\star * *}$ & & \\
\hline $\begin{array}{l}\text { Ingeniería en } \\
\text { Manufactura }\end{array}$ & $0.4642^{* *}$ & 0.0568 & & \\
\hline $\begin{array}{l}\text { Ingeniería en } \\
\text { Mecatrónica }\end{array}$ & $0.3617^{*}$ & $0.5181^{*}$ & 0.1613 & \\
\hline $\begin{array}{l}\text { Ingeniería } \\
\text { en Sistemas } \\
\text { Computacionales }\end{array}$ & $0.5750^{* * *}$ & $0.6751^{* * *}$ & $0.4300^{*}$ & 0.1867 \\
\hline $\begin{array}{l}\text { Ingeniería en } \\
\text { Sistemas Digitales y } \\
\text { Comunicaciones }\end{array}$ & $0.5208^{\star * *}$ & $0.7191^{* * *}$ & $0.6401^{* *}$ & \\
\hline
\end{tabular}




\begin{tabular}{|c|c|c|c|c|}
\hline $\begin{array}{l}\text { Programa } \\
\text { Educativo }\end{array}$ & $\begin{array}{l}\text { Mercado } \\
\text { Industrial }\end{array}$ & $\begin{array}{l}\text { Mercado } \\
\text { Servicios y } \\
\text { Comercio }\end{array}$ & $\begin{array}{l}\text { Mercado } \\
\text { Educación }\end{array}$ & Mercado Salud \\
\hline Ingeniería Física & & & & \\
\hline $\begin{array}{l}\text { Ingeniería Industrial } \\
\text { y de Sistemas }\end{array}$ & $0.5993^{* * *}$ & $0.6838^{* * *}$ & $0.5640^{* *}$ & \\
\hline Matemáticas & & & 0.1558 & \\
\hline Médico Cirujano & 0.0113 & 0.4725 & -0.1184 & $0.6311^{* * *}$ \\
\hline $\begin{array}{l}\text { Médico Veterinario } \\
\text { Zootecnista }\end{array}$ & & 0.1152 & & $0.5272^{\star *}$ \\
\hline Mercadotecnia & & $0.5205^{* *}$ & & \\
\hline Nutrición & $0.5804^{* *}$ & $0.6287^{* * *}$ & $0.4891^{*}$ & 0.3534 \\
\hline Odontología & & $0.6716^{* * *}$ & 0.0995 & $0.5097^{* *}$ \\
\hline Optometría & & 0.6003 & & $0.4311^{*}$ \\
\hline Psicología & $0.5735^{* * *}$ & $0.6568^{* * *}$ & 0.2882 & $0.6180^{* * *}$ \\
\hline Química & 0.4415 & 0.2660 & $0.4510^{*}$ & $0.4340^{*}$ \\
\hline Sociología & 0.0767 & $0.6890^{* *}$ & 0.0490 & \\
\hline Trabajo Social & $0.5120^{\text {** }}$ & $0.5376^{\star * *}$ & $0.4330^{*}$ & $0.5561^{* *}$ \\
\hline Turismo & $0.6136^{* *}$ & $0.6666^{* * *}$ & $0.5555^{\star *}$ & $0.3933^{*}$ \\
\hline Crisis Financiera & $-0.1705^{* * *}$ & $-0.2437^{* * *}$ & $-0.1398^{*}$ & -0.0878 \\
\hline (intercepto) & $-0.3124^{*}$ & $-0.3704^{\text {** }}$ & -0.2302 & $-0.3040^{*}$ \\
\hline $\begin{array}{l}\text { Numero de } \\
\text { observaciones }\end{array}$ & 216 & 279 & 243 & 144 \\
\hline R-Cuadrada & 0.1779 & 0.2000 & 0.1752 & 0.1322 \\
\hline Prueba F & 0.0183 & 0.0008 & 0.0219 & 0.2702 \\
\hline
\end{tabular}

Fuente: Elaboración propia.

Los asteriscos refieren a la significancia estadística donde $\left.{ }^{(* *}\right)$ indica que el resultado es significativo al nivel de $1 \%,{ }^{(*)}$ al nivel de $5 \%$ y $\left(^{*}\right)$ al nivel de $10 \%$.

Para robustecer el análisis, se realiza la prueba de Wald, la cual pone a prueba la capacidad explicativa sobre la existencia de la diferencia estadística entre los estimadores conjuntos, contrastando la hipótesis nula de $\alpha+=0$ (siendo j el programa educativo) que se utiliza comúnmente para contrastar hipótesis lineales a través de los parámetros. En este caso, es conocer la veracidad sobre la diferencia significativa entre los estimadores del IDL del PE y el IDL del PS por programa educativo considerado en cada mercado. Así, podremos asumir si realmente los programas educativos logran segmentarse dentro del mercado laboral en estudio. Si la afirmación anterior resulta ser verdadera, entonces podemos advertir que las condiciones laborales mejoran al cabo de dos años de haber egresado. A continuación, se muestran los resultados de la prueba de Wald. 
Víctor V. Ibáñez / Revista de la Educación Superior 48 (190) (2019) 113-137

Tabla 6. Prueba de Wald para mercados en estudio.

\begin{tabular}{|c|c|c|c|c|}
\hline $\begin{array}{l}\text { Programa } \\
\text { Educativo }\end{array}$ & $\begin{array}{l}\text { Mercado } \\
\text { Industrial }\end{array}$ & $\begin{array}{c}\text { Mercado } \\
\text { Servicios y } \\
\text { Comercio } \\
\end{array}$ & $\begin{array}{l}\text { Mercado } \\
\text { Educación }\end{array}$ & Mercado Salud \\
\hline $\begin{array}{l}\text { Administración de } \\
\text { Empresas }\end{array}$ & 0.019 & 0.000 & 0.470 & 0.466 \\
\hline Arquitectura & 0.069 & 0.000 & 0.426 & \\
\hline Artes Visuales & & & 0.020 & \\
\hline Biología & & 0.031 & 0.087 & \\
\hline Contabilidad & 0.000 & 0.000 & 0.355 & 0.059 \\
\hline Derecho & 0.904 & 0.017 & 0.599 & 0.859 \\
\hline Diseño de interiores & 0.521 & 0.075 & 0.095 & \\
\hline Diseño Grafico & 0.115 & 0.000 & 0.665 & \\
\hline Diseño Industrial & 0.011 & 0.089 & & \\
\hline Economía & 0.700 & 0.058 & 0.182 & \\
\hline Educación & & 0.996 & 0.508 & \\
\hline Enfermería & 0.682 & 0.460 & & 0.243 \\
\hline $\begin{array}{l}\text { Entrenamiento } \\
\text { deportivo }\end{array}$ & & 0.048 & 0.946 & 0.335 \\
\hline Ingeniería Civil & 0.000 & 0.068 & 0.098 & \\
\hline Ingeniería Eléctrica & 0.000 & 0.000 & & \\
\hline $\begin{array}{l}\text { Ingeniería en } \\
\text { Manufactura }\end{array}$ & 0.040 & 0.108 & & \\
\hline $\begin{array}{l}\text { Ingeniería en } \\
\text { Mecatrónica }\end{array}$ & 0.735 & 0.454 & 0.697 & \\
\hline $\begin{array}{l}\text { Ingeniería } \\
\text { en Sistemas } \\
\text { Computacionales }\end{array}$ & 0.028 & 0.000 & 0.261 & 0.487 \\
\hline $\begin{array}{l}\text { Ingeniería en } \\
\text { Sistemas Digitales y } \\
\text { Comunicaciones }\end{array}$ & 0.000 & 0.024 & 0.021 & \\
\hline Ingeniería Física & & & 0.926 & \\
\hline $\begin{array}{l}\text { Ingeniería Industrial } \\
\text { y de Sistemas }\end{array}$ & 0.000 & 0.000 & 0.061 & \\
\hline Matemáticas & & & 0.675 & \\
\hline Médico Cirujano & 0.346 & 0.789 & 0.051 & 0.054 \\
\hline $\begin{array}{l}\text { Médico Veterinario } \\
\text { Zootecnista }\end{array}$ & & 0.156 & & 0.187 \\
\hline Mercadotecnia & & 0.140 & & \\
\hline Nutrición & 0.095 & 0.059 & 0.145 & 0.769 \\
\hline Odontología & & 0.000 & 0.462 & 0.224 \\
\hline Optometría & & 0.463 & & 0.452 \\
\hline Psicología & 0.043 & 0.015 & 0.744 & 0.064 \\
\hline Química & 0.617 & 0.707 & 0.214 & 0.442 \\
\hline Sociología & 0.277 & 0.141 & 0.307 & \\
\hline Trabajo Social & 0.089 & 0.000 & 0.254 & 0.137 \\
\hline Turismo & 0.000 & 0.000 & 0.068 & 0.597 \\
\hline Crisis Financiera & 0.004 & 0.000 & 0.043 & 0.027 \\
\hline
\end{tabular}

Fuente: Elaboración propia. 
En la tabla anterior puede observarse que los programas educativos que tienen cambios significativos en el $\triangle I D L$ son aquellos que presentan una Prob. $>$ F menor a 0.05. Hay egresados de programas educativos que dependiendo en cuál de los 4 mercados estén colocados, se segmentan en el sector superior. A continuación se hace una descripción de los modelos para cada uno de los mercados.

El modelo para el mercado industrial contiene un total de 216 observaciones, con un R2 de 0.1779, el cual resulta ser bajo, pero no debe de sorprender ya que las variables explicativas son únicamente variables dummy. Sin embargo, se encuentran resultados significativos. La prueba para heteroscedasticidad indica que sí presentan problemas de heteroscedasticidad, siendo la probabilidad mayor a chi 2 de 0.000 , lo cual indica que no podemos rechazar la hipótesis nula de que la varianza de las perturbaciones es constante a lo largo de las observaciones. Para solucionar este problema se corre una regresión robusta. Se omite la dummy del programa educativo de educación debido a que su cambio relativo del IDL es el menor de todos los programas en este mercado, por lo que se toma como la base para comparar los demás programas educativos. Así, programas como administración de empresas, arquitectura, contabilidad, diseño de interiores, diseño gráfico, diseño industrial, ingeniería civil, ingeniería eléctrica, ingeniería en manufactura, ingeniería en mecatrónica, ingeniería en sistemas computacionales, ingeniería en sistemas digitales y comunicaciones, ingeniería industrial, nutrición, psicología, trabajo social y turismo tienen, en promedio, cambios significativos en el IDL de seguimiento respecto al de egreso, con diferentes niveles de significancia. Además, como se esperaba, la variable de la crisis financiera resulta ser significativa para este mercado con un nivel de significancia del 1\%. La crisis financiera afectó de manera negativa en un $17.79 \%$ en el cambio relativo del IDL de los programas que se encuentran dentro de este mercado.

El modelo para el mercado de servicios y comercio contiene un total de 279 observaciones, con un R2 de 0.2. La prueba para heteroscedasticidad nuevamente indica que se encuentran problemas al respecto, siendo la probabilidad mayor a chi2 de 0.0506 , por lo cual se corre una regresión robusta. La variable que se omite (se toma como base) es la del programa educativo de artes visuales. En este caso, se observa que los programas administración de empresas, arquitectura, biología, contabilidad, derecho, diseño de interiores, diseño gráfico, diseño industrial, economía, enfermería, entrenamiento deportivo, ingeniería civil, ingeniería eléctrica, ingeniería en mecatrónica, ingeniería en sistemas computacionales, ingeniería en sistemas digitales y comunicaciones, ingeniería industrial, mercadotecnia, nutrición, odontología, psicología, sociología, trabajo social y turismo tienen, en promedio, cambios significativos en el IDL de seguimiento 
respecto al de egreso, a diferentes niveles de significancia. Así mismo, la variable categórica que refiere a la crisis financiera resulta ser significativa para este mercado con un nivel de significancia del 1\%. Su efecto sugiere que la crisis financiera afectó de manera negativa en un $24.37 \%$ en el cambio relativo del IDL de los programas que se encuentran dentro de este mercado.

Puede apreciarse que la crisis financiera tuvo un efecto negativo mayor para los programas educativos que están dentro del mercado de servicios y comercio en relación al mercado industrial; esto tiene sentido ya que el principal canal de transmisión de la actividad económica entre naciones es el comercio de bienes y servicios y México registró la caída más abrupta en la producción de servicios y comercio en comparación con Estados Unidos y Canadá .

El tercer modelo refiere al mercado de educación, el cual contiene un total de 243 observaciones, con un R2 de 0.1752 y R2 ajustado de 0.0716. La prueba para heteroscedasticidad indica que no se encuentran problemas, siendo la probabilidad mayor a chi2 de 0.1640 . En este modelo se omite el programa educativo de historia. Se observa que los programas administración de empresas, arquitectura, artes visuales, biología, contabilidad, derecho, diseño de interiores, diseño gráfico, economía, educación, entrenamiento deportivo, ingeniería civil, ingeniería en mecatrónica, ingeniería en sistemas computacionales, ingeniería en sistemas digitales y comunicaciones, ingeniería física, ingeniería industrial, matemáticas, médico cirujano, nutrición, odontología, psicología, química, sociología, trabajo social y turismo tienen, en promedio, cambios significativos en el IDL de seguimiento respecto al de egreso. La variable de la crisis financiera resulta ser significativa con un nivel de significancia al 10\%. El efecto de la crisis financiera implicó de manera negativa un $13.98 \%$ sobre el $\triangle I D L$, siendo de menor impacto, pues el mercado de educación no está directamente conectado a los flujos internacionales de capitales por transacciones a la producción y consumo.

Por último, en el mercado de salud hay un total de 144 observaciones. Con un R2 de 0.1322 y R2 ajustado de 0.0228. La prueba para heteroscedasticidad indica que no se encuentran problemas, ya que la probabilidad mayor a chi2 de 0.1406. El dummy del programa educativo que se omite es la de ingeniería eléctrica. Los programas de administración de empresas, contabilidad, derecho, enfermería, entrenamiento deportivo, ingeniería en sistemas computacionales, médico cirujano, médico veterinario, nutrición, odontología, optometría, psicología, química, trabajo social y turismo tienen, en promedio, cambios significativos en el IDL de seguimiento respecto al de egreso. La variable de la crisis financiera no resulta ser significativa para este mercado. Asumimos 
que este sector no depende directamente de los servicios de producción, ni a inversiones extranjeras directas.

\section{Resultados.}

Se observa el $\triangle I D L$ de los programas educativos para los diferentes mercados en el periodo 2006 al 2014. Se presentan los que mayores cambios experimentaron, sin que esto sugiera dejar de lado la importancia de los demás. Así mismo, se presentan la veracidad del cambio independientemente de su cálculo relativo (Wald).

Para el mercado industrial, el programa de diseño industrial es el de mayor cambio relativo en su IDL, siendo de $75.77 \%$ con un nivel de confianza del $1 \%$ (Ver tabla 5); la prueba de Wald da cuenta de ello (Tabla 6). Esto implica que si existe diferencia estadística entre el efecto en el cambio relativo en relación con la constante, se asume que las condiciones laborales mejoran al paso de dos años después de haber egresado. De esta misma forma se podrían entender los próximos resultados expuestos con las mismas condiciones. El programa de contabilidad tiene un cambio relativo en su IDL de $63.53 \%$ con un nivel de confianza del 1\%; Wald encuentra que los parámetros estimados de este programa y la constante también resultan ser significativos. Existe diferencia estadística en el efecto del cambio relativo. Para turismo, su $\triangle I D L$ es de $61.36 \%$ con un nivel de confianza del $5 \%$, que es apoyada por la prueba de Wald e indica que sus condiciones laborales mejoran al paso de dos años de los egresados. El programa de ingeniería industrial y de sistemas tiene un $\triangle I D L$ de $59.93 \%$ con un nivel de confianza del 1\%, donde la prueba Wald apoya dicho cambio. Por último, está el programa de nutrición, el cual presenta $\triangle I D L$ de $58.04 \%$ con un nivel de confianza del 5\%; la prueba de Wald es significativa. Se asume un cambio en la segmentación de los egresados de este programa.

En el caso del mercado de servicios y comercio, los cinco con mayor cambio relativo en su IDL son el programa de ingeniería eléctrica con un $92.2 \%$ al $1 \%$ de confianza. La prueba de Wald predice que los parámetros son significativos; experimenta un cambio en la segmentación dentro del mercado. Haber egresado de diseño industrial, tiene un $\triangle I D L$ de $78.78 \%$ con un nivel de confianza del $5 \%$; sin embargo, la prueba de Wald no resulta ser significativa. No hay diferencia estadística y evidencia de un cambio en la segmentación de este programa. Entrenamiento deportivo tiene un $\triangle I D L$ de $73.84 \%$ con un nivel de confianza del 1\%; según la prueba de Wald el cambio es significati- 
vo. El programa de ingeniería civil obtiene un $\triangle I D L$ de $73.56 \%$ con un nivel de confianza del 1\%; la prueba de Wald indica que los estimadores y el intercepto no son significativos. No hay evidencia de un cambio en la segmentación de los egresados de este programa. Arquitectura tiene un cambio relativo en su IDL de $72.67 \%$ (al 1\% de confianza); la prueba Wald nos advierte que los parámetros de este programa son significativos.

Al analizar los resultados de los egresados del mercado de educación, se observa un mayor cambio relativo en su IDL, pero tres de ellos no pueden probar estadísticamente dicho cambio. Los programas de artes visuales e Ingeniería en sistemas digitales y comunicaciones tienen un $\triangle I D L$ de $64.3 \%$ y $64.01 \%$ respectivamente (con nivel de confianza del 5\% para ambos), donde la prueba de Wald mostró parámetros consistentes en los dos programas; se sugiere que hay un cambio en la segmentación de los egresados de estos programas. Para e ingeniería industrial y de sistemas, su cambio relativo es de $56.4 \%$ (confianza del 5\%); al contrario que los programas anteriores, Wald indica que sus cambios entre estimadores no resultan ser significativos. No hay evidencia de un cambio en la segmentación. Turismo y biología, tiene un $\triangle I D L$ de $55.55 \%$ y 53.44 respectivamente, ambos con un nivel de confianza del $5 \%$. Sin embargo, Wald confirma que no hay evidencia de dicho cambio, debido a que los parámetros no son significativos para los dos programas.

Dentro del mercado de salud, programas educativos presentan un mayor cambio relativo en su IDL. Sin embargo, hay egresados de programas íconos que no logran segmentarse rápidamente. Por ejemplo, el programa de médico cirujano, que tiene un $\triangle I D L$ de $63.11 \%$ con un nivel de confianza del $1 \%$, la prueba Wald indica que los parámetros no resultan ser significativos. Este efecto pareciera ser algo extraño, debido a que el mercado de salud naturalmente es donde se colocan los médicos. No obstante, habría que tomar en cuenta que al paso de dos años (en esta disciplina) no es suficiente para notar cambios significativos en sus condiciones laborales. Los egresados de Contabilidad y Psicología corren con la misma suerte, ya que su $\triangle I D L$ es de $62.44 \%$ y $61.8 \%$ para cada uno, con un nivel de confianza del $1 \%$. Wald muestra que no hay evidencia de su cambio en ambas. El programa de trabajo social y médico veterinario zootecnista tiene un cambio relativo en su IDL de $55.61 \%$ y $52.72 \%$ respectivamente con un nivel de confianza del 1\%. Analizando la prueba de Wald para ambos programas, encontramos que los estimadores tampoco resultan ser significativos, así que no hay evidencia de un cambio en la segmentación de los egresados de este programa. Los resultados son muy interesantes, ya que ningún programa muestra evidencia estadística de los cambios relativos en este mercado en particular siendo los de mayor variación. 


\section{Conclusiones.}

De acuerdo a los resultados obtenidos se observa que la hipótesis inicial de este trabajo se cumple en los egresados de programas educativos que tienen un cambio significativo en su IDL. Se puede verificar el cambio en sus condiciones laborales a dos años de haber egresado. Desde el inicio se sospechaba de la existencia de una segmentación de mercado en los egresados de programas al ver cómo la proporción de egresados que indican estar en el sector formal superior es mayor en el PS que en el egreso para cada uno de los componentes del IDL.

Esos cambios son posibles gracias a que los egresados de programas educativos se colocan en los mercados para los que fueron formados (aunque también hay programas que sobresalen en mercados que no son directamente su campo principal). Por ejemplo, las ingenierías tienen un cambio significativo dentro del mercado industrial (como era de esperar), pero también demuestran tener buenas condiciones dentro del mercado de servicios y comercio, siendo un cambio significativo en el IDL que sugiere un grado de adaptación y versatilidad en la que se han formado.

Para el caso de los programas que están enfocados al mercado de servicios y comercio es notable observar que tanto administración, arquitectura, contabilidad, derecho, psicología, trabajo social y turismo tienen cambios significativos que llevan a su segmentación. Esto nos propone que los resultados encontrados parecen ser correctos y coherentes en el sentido de que los egresados de los programas educativos tienen incrementos en su IDL (y por lo tanto un cambio en su segmentación hacia mejores condiciones laborales) y lo hacen dentro de los mercados a los que van dirigidos.

Podemos observar que la crisis financiera tuvo efecto significativo en el mercado industrial y servicios y comercio, siendo para este último con un mayor efecto, comparado con el mercado industrial. Para el mercado de educación se encuentra un efecto también de la crisis financiera, pero con menor impacto. Los resultados sugieren que para el mercado de salud, la crisis financiera no tuvo ningún efecto sobre el desempeño de los programas educativos ahí colocados.

En México falta mayores investigación, difusión y trabajos que aborden los temas de instituciones de educación en su calidad de egreso y el mercado laboral a donde están dirigidos. Hacer un "match" entre lo que se forma e instruye y lo que se requiere en el mercado laboral es una tarea pendiente. 
